NBER WORKING PAPER SERIES

\title{
RAISING THE BAR FOR COLLEGE ADMISSION: NORTH CAROLINA'S INCREASE IN MINIMUM MATH COURSE REQUIREMENTS
}

\author{
Charles T. Clotfelter \\ Steven W. Hemelt \\ Helen Ladd
}

Working Paper 21926

http://www.nber.org/papers/w21926

\author{
NATIONAL BUREAU OF ECONOMIC RESEARCH \\ 1050 Massachusetts Avenue \\ Cambridge, MA 02138 \\ January 2016
}

We are grateful to Yang Zhou and Ying Shi for research assistance, to the North Carolina Education Research Data Center, the North Carolina Department of Public Instruction, and the University of North Carolina General Administration for assistance in obtaining data, and to the Gates Foundation and the American Institutes for Research/CALDER for financial support. The views expressed are those of the authors and are not necessarily those of any organization. The views expressed herein are those of the authors and do not necessarily reflect the views of the National Bureau of Economic Research.

NBER working papers are circulated for discussion and comment purposes. They have not been peerreviewed or been subject to the review by the NBER Board of Directors that accompanies official NBER publications.

(C) 2016 by Charles T. Clotfelter, Steven W. Hemelt, and Helen Ladd. All rights reserved. Short sections of text, not to exceed two paragraphs, may be quoted without explicit permission provided that full credit, including $\odot$ notice, is given to the source. 
Raising the Bar for College Admission: North Carolina's Increase in Minimum Math Course Requirements

Charles T. Clotfelter, Steven W. Hemelt, and Helen Ladd

NBER Working Paper No. 21926

January 2016

JEL No. I21

\begin{abstract}
We explore the effects of a statewide policy change that increased the number of high school math courses required for admission to any of North Carolina's 15 public four-year institutions. Using administrative data on cohorts of 8th grade students from 1999 to 2006, we document and exploit variation by district over time in the math course-taking environment encountered by students. Within an instrumental variables setup, we examine effects of the policy change on students grouped into deciles defined by their 8th grade math test scores. First, we find that students took more math courses in high school following the state's announcement, with relatively larger increases in the middle and bottom deciles of students. Second, we conclude that increased math course-taking in high school led to increases in college enrollment rates that were not uniform across the 15 branch campuses. In particular, we observe the largest increases in the deciles of student achievement from which universities were already drawing the bulk of their enrollees. Finally, for upper-middle decile students, we find limited and noisy evidence that increased math course-taking in high school boosts post-enrollment college performance as measured by a student's GPA or the likelihood of majoring in a STEM field.
\end{abstract}

Charles T. Clotfelter

Sanford School of Public Policy

Duke University

Rubenstein Hall Room 178

201 Science Drive

Box 90312

Durham, NC 27708

and NBER

charles.clotfelter@duke.edu

Steven W. Hemelt

Department of Public Policy

University of North Carolina - Chapel Hill

Abernethy Hall, Campus Box 3435

Chapel Hill, NC 27599

hemelt@email.unc.edu
Helen Ladd

Sanford School of Public Policy

Box 90245 Duke University

Durham, NC 27708

hladd@duke.edu 


\section{Introduction}

In April 2000 the state of North Carolina announced an increase in the minimum number of math courses students would need to take to be considered for admission as undergraduates to any of the University of North Carolina's 15 four-year branch campuses. Previously, students had been required to take at least three math courses in high school to be eligible for admission. The new standard required at least four math courses and applied to all students graduating from high school in the 2005-06 school year or after. ${ }^{1}$ The state justified this increase in required math preparation by arguing that it would improve college completion rates. But there has been no assessment to date whether these hopes have in fact been realized or, indeed, whether the beefed up requirements had any effect at all. After all, it is likely that many students in the state would have taken four math courses in high school whether or not the state had increased the mandated number.

The purpose of this paper is to assess the effects of this increase in the mandated minimum number of math courses. This assessment entails two separate questions. One is whether the policy affected actual course-taking among high school students. In exploring this question, we are attentive to the likelihood that the new standard might have a bigger effect on some groups of students than on others. Another question is whether any such changes in high school course-taking, together with the threat of being denied admission, affected college enrollment patterns or students' choices or performance once enrolled. Enrollment refers to whether and where students went to college within the University of North Carolina (UNC) system. Beyond enrollment, we examine several in-college outcomes, including students' choice of major, their grades in college, and graduation.

\footnotetext{
${ }^{1}$ For a description of the minimum requirements for UNC, see Minimum Admission Requirements, http://www.northcarolina.edu/?q=prospective-students/minimum-admission-requirements, 10/27/15.
} 
We cannot simply compare the college enrollment and college success of students with different numbers of high school math courses, however, because the decisions students make are influenced by a number of factors that also affect their college performance. Instead we use differences in course offerings and rates of change by district, year, and level of math aptitude as instruments in our student-level models explaining enrollment by branch university, choice of major and post-enrollment performance. These differences are exogenous to the student, even though the student herself had choices regarding how many math courses to take and when.

The study extends the existing literature in three ways. First, it sheds light on how a policy change at the university level affects the behavior of students in high school. Second, it extends the literature on the effects of math course-taking in high school to college enrollment and college success. Third it makes a methodological contribution by its close attention to the estimation of causal relationships that leverage the plausibly exogenous variation that arises as a result of the policy change.

Our findings fall into three groups. First, the evidence is consistent with the expectation that the increased requirements would influence the number of high school math courses taken by at least some students. Throughout our analysis we categorize students by their math aptitude as measured by their performance on the required $8^{\text {th }}$ grade math end-of-grade test, with performance divided into deciles from low to high. Many students, particularly those in the higher deciles, were already taking four math courses by the time the minimum number was increased, so the new requirement presumably had no direct effect on them. But in eight of the 10 deciles we observed greater-than-expected increases in the share of students who, using the proxy we had (whether a student had taken Algebra II by $11^{\text {th }}$ grade), were in a position to meet 
the new four-course standard. We cannot prove that these increases were due to the policy, but it is reasonable to think that at least most of them were.

Second are findings related to whether the increase in math courses affected whether students enrolled in one of the state's public university campuses and, if so, where. Because the increases in math courses were greatest for students with $8^{\text {th }}$ grade math scores in the middle deciles, one might have expected that the branch campuses whose students traditionally come from those deciles would have experienced the biggest increases in enrollment due to the changes in math course-taking in high school. Surprisingly, we did not find that. Instead, we find increases in predicted enrollment due to changes in math course-taking across all campuses, distributed differently across math achievement deciles. Each branch experienced increases in predicted enrollment, but those increases tended to be for students in the deciles that were already most common at those branches. For the branches that have traditionally drawn from deciles below the median, the newly stimulated enrollments came from those deciles. For the two branches with the highest shares of students from the top deciles before the policy change, the new policy stimulated new enrollment, and it was mainly in those same top deciles. Despite the general tendency before the change for top-decile students to have taken four math courses, many top decile students apparently had not been doing so, especially in school districts that had not pushed such students to do so in the past. Once the policy change was enacted, such districts beefed up their math pathways, causing more top students to take more math. Conceivably, the new requirement caused these top students to consider attending the leading research universities at Chapel Hill or NC State instead of one of the branches closer to their homes.

We believe this second set of findings represent causal effects of the policy change. We express these findings as predicted changes in enrollment rates, based as they are on results from 
an instrumental variables model for 10 different deciles of students for each of 15 different branches. Comparing these predicted changes to the actual changes in enrollment rates by decile and branch reveals some big differences, suggesting other forces were at work as well as this policy. One force was capacity. Few of the branches of the university were prepared for very large changes, up or down, in total enrollment. Therefore, it would not be surprising if their admissions decisions became tougher or easier as a result of changes in student demand. Other forces, including demand for admission spots from out of state, the effects of SAT coaching, or the extraordinary rise in the incomes of the most affluent families, could easily have overwhelmed the effect of the policy itself.

The third set of findings relate to whether the minimum course requirement affected the behavior of students once they enrolled in one of the branches. Here the results are less broadbased than for the other analyses. We find some evidence that the policy change increased the likelihood that high decile students would major in a STEM field, but reduced the likelihood of low decile students of doing so. Further, we find that the program raised the GPA of students in deciles 8 and 9, but had at most limited effects on four-year graduation rates.

The paper begins by giving some of the background to the policy announced in 2000 . Next we review the small literature on the relationship between math taken in high school to subsequent success in college. Then we describe the data set we use to analyze the policy. In the fifth section, we examine patterns of course-taking in the state's high schools, looking for evidence that the state's new mandate affected those patterns. Section VI describes the instrumental variables approach that we use to estimate the effects of the increase in the minimum course requirement. Section VII discusses the potential for differences in impact across the system's 15 branches on college enrollment and presents instrumental variable 
estimates of the effect of variations in the rigor of high school math regimes encountered by high school students across the state over time. ${ }^{2}$ In section VIII we turn our attention to the possible effects of the new mandate on college outcomes. The paper's last section summarizes our approach and findings.

\section{The State's Rationale for Raising the Bar}

The state of North Carolina was a leader in pushing for higher performance in its public schools, adopting rigorous statewide standards for K-12 curricula in the 1990s and following up by adopting a muscular assessment regime. At the heart of this assessment system was a host of annual tests for all public school students in elementary and middle schools beginning in $3^{\text {rd }}$ grade as well as high school students taking several key courses in math, English, and other subjects. In step with these top-down policies for K-12 schools, the state also established minimum course requirements for students wishing to go on to attend one of the state's 15 public four-year colleges and universities, which collectively comprise the University of North Carolina system. By 1990 the state was requiring that students hoping to enroll in any of the 15 branches needed to complete four courses in English and at least three courses each in mathematics and science and two in social science. The three math courses had to include Algebra I and II plus either geometry or a course for which Algebra II was a prerequisite.

By the end of the 1990s a consensus among education policy makers in the state had evidently developed that this three-course math requirement needed to be strengthened. This resolve was spurred in part by state leaders like Governor Jim Hunt, who saw improved education as central to the state's ambitions for economic development. Advocates of stiffer

\footnotetext{
${ }^{2}$ The University of North Carolina has 17 branch campuses, one of which is a two-year senior high school for science and math and one of which, the North Carolina School of the Arts, combines high school grades with college. We omit these two institutions in the present study. The remaining 15 institutions are listed in Appendix Table A1.
} 
math requirements cited research showing a strong correlation between high school math coursetaking and success in college. ${ }^{3}$ As calls for more math reverberated in political circles, high school graduation requirements in North Carolina remained unchanged for $9^{\text {th }}$ graders entering between 1999/00 and 2008/09. During this period students could choose from four "tracks" that led to a high school diploma. Only one of the four tracks, "College/University Prep," required four math credits. The others demanded only three credits of math. ${ }^{4}$ Therefore, the changes adopted by the state of North Carolina in 2000 regarding eligibility for entry into the four-year public university system did not overhaul the requirements for a high school diploma for everyone, but rather put teeth into the "college prep" recommendation for students interested in going to college. ${ }^{5}$

\section{Research on the Relationship between High School Math and College Success}

A recent focus of the literature on mathematics course-taking has been on early exposure to algebra (Alderman, 2006), since knowledge of algebraic concepts is a precursor to a variety of more advanced math classes. One line of inquiry explores the effects of algebra placement policies on students' subsequent academic performance during high school (e.g., Clotfelter, Ladd and Vigdor, 2015; Nomi, 2012; Allensworth et al., 2009). Another avenue examines the effects of more (or "double-dose") algebra on short-run performance (Nomi and Allensworth, 2009) as well as long-run outcomes like high school graduation and college entry (Cortes, Goodman, and Nomi, 2015). Though we do not study the direct benefits of more algebra, we use completion of Algebra II by $11^{\text {th }}$ grade as a proxy for the ability and time to complete four courses of math in

\footnotetext{
${ }^{3}$ Much of the early research linking increases in math instruction with later beneficial outcomes were based on correlations rather than full causal models. See, for example, Rose and Betts (2001).

${ }^{4}$ NC Public Schools, High School Graduation Requirements (2012): http://www.ncpublicschools.org/docs/curriculum/home/graduationrequirements.pdf

${ }^{5}$ In this sense they differed significantly from changes in other states including Michigan which in 2006 adopted the "Michigan Merit Curriculum" (MMC). The MMC emphasized academic preparation in math and science. In terms of mathematics, the MMC increased the required number of math courses from three to four for all high school students seeking a diploma.
} 
high school. Our focus is on the postsecondary effects of encouraging high school students to take more math classes.

There is little evidence on how changes in policies at the university level affect high schools. In addition, there is limited causal evidence on how high school course-taking affects postsecondary success. Long, Conger, and Iatarola (2012) found that taking just one rigorous course early in high school increased subsequent academic performance and the likelihood of attending a four-year college, relative to taking no rigorous courses (p. 314). In other work, these authors determined that differences among college-students in the highest high school math course taken explain at least one-fourth of racial, ethnic, and poverty gaps in readiness for college-level math (Long, Itatarola, Conger, 2009). Finally, recent work suggests that as the number of math courses required of students rises, so do their earnings, especially for economically disadvantaged students (Goodman, 2012).

IV. Data

We analyze student-level administrative data collected by two state agencies, the Department of Public Instruction, which oversees the state's elementary and secondary schools, and the University of North Carolina General Administration, which oversees all of the state's four-year colleges and universities. Through the good offices of those agencies and the North Carolina Education Research Data Center, student records from the K-12 public schools were linked to student records from the UNC system, stripped of identifying information, and made available to us for this project. Our data set is made up of several cohorts of students who were in one of the state's public schools - including both charter schools and traditional public schools in $7^{\text {th }}, 8^{\text {th }}$, and $9^{\text {th }}$ grades. We organized students by cohort according to the score they made on 
the statewide math achievement test in their first spring as $8^{\text {th }}$ graders. ${ }^{6}$ A student who started $8^{\text {th }}$ grade in the 1998-99 school year, for example, belongs to a cohort we refer to as the $19998^{\text {th }}$ grade cohort, or simply the 1999 cohort. As a part of the state's assessment program, all $8^{\text {th }}$ graders in North Carolina's public schools take end-of-year tests in math and reading in the spring of their $8^{\text {th }}$ grade year; for a student in the $19998^{\text {th }}$ grade cohort this test would have been administered in the spring of 1999 . In total, we employ data on $8^{\text {th }}$ grade cohorts from 1999 to 2006.

For each cohort, we divided all the $8^{\text {th }}$ grade math test-takers in the state into deciles and assigned each student accordingly. We also identified the school district containing each student's $8^{\text {th }}$ grade school, or, in the case of charter school students, the district where the student's charter school was located. The K-12 administrative data also contain information on student characteristics, such as gender, race and ethnicity, eligibility for subsidized lunches (an indicator of low family income), and parents' educational attainment. ${ }^{7}$ For students who subsequently enrolled in one of the university system's 15 branches, we also have detailed information on college course taken, grades, declared major, and graduation.

Crucial to our analysis is information on the mathematics courses students took, because the number of such courses relates to the mandate whose effect we wish to measure. Ideally we could gather this information simply by examining students' middle school and high school transcripts. Unfortunately, such transcript information has only become available for recent

\footnotetext{
${ }^{6}$ Any student repeating $8^{\text {th }}$ grade was assigned to the cohort for the first year in that grade. In addition, we omitted students who were not also in the public school system in the $7^{\text {th }}$ grade, since some students take Algebra I in $7^{\text {th }}$ grade, and our proxy for course-taking requires knowing whether students took this course. We limited the sample to those who remained in public school through the $9^{\text {th }}$ grade to eliminate those who dropped out at an early age or who enrolled in private high schools. We retained in the sample students missing socioeconomic or demographic information, adding indicator variables to signify the omission of those variables.

${ }^{7}$ We were forced to drop the $20058^{\text {th }}$ grade cohort for Wake County because of an obvious but unexplained data problem for that cohort. The number of observations contained in the raw data for that one cohort was less than 5\% the size of either cohort immediately preceding or following it, suggesting a serious data problem.
} 
years, not enough years to be useful for this study. We could not, therefore, count every math course a student took and thus cannot determine whether any particular student actually achieved the newly mandated four-course minimum either before or after the mandate took effect. However, we were able to do the next best thing: we could assess whether a student was in a good position to meet that minimum course requirement by using data we had on end-of-course tests to check whether a student took one crucial math course that constitutes the necessary foundation for any student who wishes to take four or more math courses before college Algebra II. As noted above, the wording of North Carolina's new four-course minimum explicitly identified this course as a fundamental building block, by requiring at least "one unit beyond Algebra II." Taking this course by $11^{\text {th }}$ grade therefore turns out to be a good indicator of a student's intention and ability to complete the minimum of four math courses by the end of high school. Accordingly we adopt this indicator - having taken the end-of-course exam in Algebra II by $11^{\text {th }}$ grade - as our proxy for the intent and ability to comply with the four-course minimum.

To assess the validity of this proxy, we compared it to actual course-taking using data for students in the $20068^{\text {th }}$ grade cohort, a cohort for which complete transcript data are available. This comparison showed that our proxy worked for roughly $83 \%$ of students in the 2006 cohort, correctly predicting completion of at least four courses for those who completed Algebra II by $11^{\text {th }}$ grade and predicting failure to complete four courses for those who did not complete Algebra II by $11^{\text {th }} .8$ It is worth noting that not all districts configure their high school math

\footnotetext{
${ }^{8}$ In $14 \%$ of the cases, students took Algebra II end-of-course test by $11^{\text {th }}$ grade but did not complete the minimum four math courses by the end of $12^{\text {th }}$; in $3 \%$ of the cases they did not complete Algebra II by $11^{\text {th }}$ grade but ended up completing four courses by the end of high school, presumably by going to summer school or doubling up in their senior year. In comparison to the Algebra II criterion we employed, and its $83 \%$ accuracy as a proxy, the accuracy rates for two alternative criteria were: $80 \%$ for having taken Algebra I and II plus Geometry by $11^{\text {th }} ; 82 \%$ for having taken Algebra II plus Geometry by $11^{\text {th }}$.
} 
courses the same way, instead using a parallel set of math courses. But students subject to this parallel regime end up taking the same end-of-course test, thus making it straightforward to apply our criterion to them as well. ${ }^{9}$

\section{Patterns of Course-Taking in High School}

Before asking whether the state's increase in the minimum course requirement had any effect on enrollment or college performance, we first address the logically prior question: did the mandate have any effect on patterns of course-taking in high school? After all, if course-taking was not affected, it is very unlikely that there could be any other ramifications. To get at this prior question, it is helpful to recount some of the details surrounding the policy and the timing of its rollout.

The new minimum was officially adopted by the university system's governing board in April 2000. In the weeks following the decision, the UNC system president alerted state leaders, and plans were made to hold town hall meetings around the state to discuss implementation. By November, a statewide committee had been formed to explore ways to modify high schools' math sequences. ${ }^{10}$ Given this timing of events, the very earliest any district or high school in the state could possibly have made changes to accommodate the new policy would have been the fall of 2000 , changes that would allow any $9^{\text {th }}$ graders starting that fall to achieve the four-course

\footnotetext{
${ }^{9}$ The vast majority of districts offer the sequence of Algebra I, Geometry, and Algebra II. But a few march to a different drummer, and designate their high school math courses using the term "integrated math," wherein Integrated Math I roughly corresponds to Algebra I, II to Algebra II, and III to Geometry. In issuing the mandate four-course minimum, the state actually provided for three different sequences of courses, since not all districts offer the same set of high school math courses. The sequence used by most districts is Algebra I, followed by Algebra II and Geometry. The corresponding first option specified by the state for complying with the new four-course mandate was those three courses plus "one unit beyond Algebra II." The second option specified by the state was to take Algebra I, Algebra II, and two courses beyond Algebra II. A third option was offered by the few districts using the "integrated math" designation. Thus the third route allowed by the state was to take Integrated Math I, II, and III, plus one unit beyond Integrated Math III. In fact very few districts use this sequence of courses, and those that do have their students take the same end-of-course tests as those in the conventional sequence.

${ }^{10}$ Information on min course requirements found at: http://old.northcarolina.edu/aa/admissions/requirements.htm 7-1915
} 
standard. For students whose anticipated sequences of courses would have left them short of that new standard, those sequences would need to change. These new $9^{\text {th }}$ graders in the fall of 2000 were therefore members of the $20008^{\text {th }}$ grade cohort, the first cohort whose math courses could have been influenced by the policy - and then only if their district was eager to adopt the new standard even though it was not yet a requirement. A district did not have to make changes this fast, since the state provided for a two-year transition period. If a district waited until the last minute to comply with the new four-course standard, it would have to make any necessary changes in time to accommodate $9^{\text {th }}$ graders starting high school in the fall of 2002 ; these $9^{\text {th }}$ graders were members of the $20028^{\text {th }}$ grade cohort.

Because of the two-year interval between the announcement of the new policy and its actual enforcement, we have the opportunity to examine the effect of increased math coursetaking separately, before the policy's layer of enforcement took hold. Unlike the $19998^{\text {th }}$ grade cohort, which had started high school with no hint of the policy change to come, the 2000 and 2001 cohorts knew that the requirement would soon be increased, but not soon enough to apply to them. Although their own entry into UNC would not be imperiled, however, they could nevertheless have been influenced by repercussions in their schools resulting from the policy's announcement. Districts could well have made changes in the timing and coverage of their math courses in anticipation of the new requirement. Parents and students could have realized that education leaders believed it was desirable to take more math courses. Whatever the mechanism, increases in math course-taking by these two transition-period cohorts - which came about without any change in formal entry requirements - could have real consequences. These amount to a pure course-taking effect. 
But for cohorts after 2001, the state's new policy added teeth to this pure course-taking effect, in the form of the penalty associated with noncompliance: denial of admission to UNC. To summarize, we can identify three phases. First, for $8^{\text {th }}$ grade cohorts up to and including 1999, the increase in minimum courses could have no effect. Second, for the 2000 and 2001 cohorts in the transitional period, the policy change could have had an effect, but only by way of induced increases in course-taking, not by any threat of penalty if the new standard was not met. Third, the new minimum would have had its full effect beginning with the 2002 cohort, by laying the sanction on top of the induced increase in math course-taking.

During the second and third of these periods the policy was unlikely to have influenced the course-taking of all students equally. The highest achieving students were most likely already planning to take at least four math courses in high school. For them, the policy was unlikely to have had a large effect. At the other end of the achievement spectrum, many students were probably not going to take more than one or two math courses in any case. So they were similarly unlikely to be influenced by a policy that mandated four. Consequently we would expect the effect to be largest, if it showed up anywhere, in the middle deciles, where students were already on the borderline between taking three or four math courses.

To see whether the observed patterns of course-taking suggest that the policy had any effect at all on course-taking, we examine trends for the state as a whole in the percentage of students who had completed Algebra II by $11^{\text {th }}$ grade (our proxy for the ability to achieve the four-course standard). We examine the span of years over which they policy would have had its biggest effect, with its combination of the course-taking and the enforcement effects. If the new four-course standard had any effect on course-taking, therefore, we would expect no unusual increases up to 1999, an extraordinary increase between 1999 and 2002, and no unusual 
increases after 2002. Essentially, this progression was like an interrupted time trend. Any increases in course-taking before 2000 or after 2002 could not be due to the policy.

Figure 1 shows trends for four selected deciles, beginning with students in the 1999 cohort and ending with those in the 2007 cohort. To make clear our expectations about when the four-course mandate might have had its effect, if any, we divide the cohorts between those whose course-taking could reasonably have been increased and those cohorts for which we expect no boost because they encountered no change in the minimum number. Among the deciles shown in Figure 1, all but one (the $9^{\text {th }}$ ) manifest the pattern we would expect if the mandate had an effect on course-taking: an increase from the 1999 to 2002 cohorts, followed by no increase. Although these patterns do not prove that the increase in the minimum course requirement caused the observed change in course-taking, the patterns are certainly consistent with that hypothesis. For the $9^{\text {th }}$ decile, however, it is a different story. Little if any change in course-taking is evident, suggesting that the policy probably had very little impact on the sequence of math courses taken by high-achieving students.

Table 1 provides a closer look, by decile of math achievement, at the changing share of students who took Algebra II by $11^{\text {th }}$ grade. By looking separately at each decile, we can test our intuition that the mandate would have had a bigger effect on some deciles than others. A rough test for whether the policy had any bite is to compare the change in course-taking during the three-year window when it would have had its maximum impact with the subsequent three-year window, by which time the policy had been wholly incorporated and thus not likely to cause additional increases in math courses taken. For all deciles combined, the percentage of students who had taken Algebra II by $11^{\text {th }}$ grade increased from $53.1 \%$ for the 1999 cohort to $60.9 \%$ for the 2002 cohort, an increase of nearly 8 percentage points. Over the next three years, however, 
the increase was just 1.4 percentage points, a pattern consistent with the hypothesis that the fourcourse mandate did push districts and schools to increase the number of foundational math courses students took in high school.

When examined by decile, these comparisons strongly suggest that the policy had its principal effect at the bottom and middle of the math aptitude distribution, not at the top. For each of the deciles from 1 to 6 , t-tests show that increases in the propensity to take Algebra II increased by more from the 1999 to the 2002 cohorts than over the subsequent three cohorts. Notably, the rate of taking Algebra II by $11^{\text {th }}$ grade by students in the highest three deciles actually increased in the latter period, a pattern unlikely to have been the result of the new minimum course requirement. ${ }^{11}$

Given the considerable autonomy accorded to local school boards, even in states with more than the average amount of central control, such as North Carolina, practices often differ across districts. When we look beneath the state totals in Figure 1, we behold a good bit of variation in our course-taking proxy, both in the propensity of students in a given decile to take Algebra II by $11^{\text {th }}$ grade and in its change over time. We illustrate this variety across districts with scatterplots that compare this percentage for the 1999 and 2002 cohorts, that is, for the last cohort untouched by the new mandate and the first cohort for whom the mandate would have its maximum impact. We plot these percentages for the state's five largest school districts (Wake County, the district containing Raleigh; Charlotte-Mecklenburg; Cumberland, containing Fayetteville; Guilford, containing Greensboro and High Point; and Winston-Salem/Forsyth), and

\footnotetext{
${ }^{11}$ Unless it reflects [that] the laggard districts in the east and west finally got their courses set up for students who wanted to take the required four.
} 
we split the remaining 112 districts by urban and rural, divided among the state's three regions: mountains, Piedmont, and coastal plain (or coastal). ${ }^{12}$

Consider, for example, the proportion of decile 2 students who had taken Algebra II by $11^{\text {th }}$ grade, shown in Figure 2. As this scatterplot shows, North Carolina's school districts differed in the share of students in the 1999 cohort who achieved this criterion. Most districts had increased this share by the time their 2002 cohort had completed $11^{\text {th }}$ grade, but by varying degrees. Whereas fewer than $5 \%$ of decile 2 students in rural districts in the mountains had achieved it, the share who did so in Charlotte-Mecklenburg was more than $20 \%$. Of greater significance is the fact that in most districts and district groups the share of students taking Algebra II by $11^{\text {th }}$ grade increased between the 1999 and 2002 cohorts, signified in the graph by points above the diagonal line. All but one of the points indicate increases, and the increases were largest in the state's five largest districts, suggesting perhaps that large and sophisticated districts were quick to make the adjustments necessary to accommodate the new standard. In Guilford County the propensity for students to take Algebra II by $11^{\text {th }}$ grade increased markedly, by more than 20 percentage points. This tendency to increase these shares suggests - but does not prove — that the new mandate had an effect, albeit a varying one, on districts and their students. A similar pattern can be seen for students in decile 4, with the big five districts, along with the other urban districts in the Piedmont recording the largest increases in the share of students taking Algebra II by $11^{\text {th }}$ grade. The district with the largest increase was Wake, which saw its share rising about 25 percentage points. As was the case for decile 2 , the laggards were the districts in the mountains and the coast, both urban and rural.

\footnotetext{
${ }^{12}$ For a description of these regions and a list of counties contained by each, see Clotfelter, Ladd and Vigdor (2003, Figure 1 and Table A1).
} 
For decile 6, the shares of students taking Algebra II by $11^{\text {th }}$ grade were higher, and the increases generally smaller. Again, the five big urban districts led the way in increases, with the share for Wake's decile 6 students rising more than 15 percentage points. Here, too, districts in the mountains and coastal plain showed little change.

For students near the top in math achievement, the story is quite different. As shown in Figure 5, the share of students in decile 9 who had taken Algebra II by $11^{\text {th }}$ grade was already high before the policy was announced - more than $80 \%$ in all districts and district groups - and that share hardly budged in most districts after the new standard was announced. The only two sizable changes were an increase of some 8 percentage points in rural Coastal districts and 5 points in Wake. ${ }^{13}$

Was the new policy responsible for the changes observed? It seems likely it was at least to some extent. But it is impossible to tell for sure, because at the same time districts were responding to the newly promulgated standard for admission to the UNC system, educators across the country were being urged to increase the rigor of math education. Ultimately, it is impossible to disentangle the effects of the policy from this growing sentiment in education circles.

In the remainder of the paper, we focus our attention on the effects of two conceptually distinct potential ramifications of the new minimum. The first is increases in math courses taken, leaving unsettled exactly what share of those increases was a consequence of the state's decision to increase the minimum number of high school math courses required for university admission. The second ramification is the bar on admission for non-compliers. For both, it remains

\footnotetext{
${ }^{13}$ To review the changes at all deciles, Appendix Table A1 presents the 1999 proportions, by decile and district or district group, of students who finished three math courses by $11^{\text {th }}$ grade. Appendix Table A2 shows the change in these proportions between 1999 and 2002.
} 
important to ask whether changes in the math course sequences offered by districts across the state, whatever their origin, had effects on students' rates of entry into the University of North Carolina or their success once there.

\section{Instrumental Variables Approach}

We wish to estimate the effect of increases in high school math courses taken by the state's public school students on patterns of enrollment in the UNC system and students' choices and performance after enrollment. Owing to the two-year transition period between announcement and implementation, we estimate separately the effect of course-taking, using the behavior of the cohorts who came along during the transition period, as well as the policy's combined effect, for later cohorts. All of what follows in this section applies to the estimation we undertake separately for these two sets of cohorts.

We estimate the effects of changes in the course environment encountered by students, by cohort, district, and decile. We are able to observe successive cohorts of students in North Carolina passing through grades in 115 different districts whose high schools subject differing shares of their students to more or less rigorous sequences of math courses. ${ }^{14}$ Purely as a result of a student's year of birth and location in the state, she faced different probabilities of encountering a sequence of math courses sufficient to qualify for admission to the University of North Carolina. In other words, the rigor of the math course sequences confronting any student was exogenous to that student, since it was not influenced by her own actions.

To assess the effect on college enrollment of the state's decision to require another math course, this logic suggests an instrumental variables (IV) setup in which a natural instrument for a student's math course-taking experience is the share among all the students in each student's

\footnotetext{
${ }^{14}$ For purposes of aggregating at the district level, we include in each district the charter schools located within its boundaries.
} 
cohort, district, and decile group who completed Algebra II by grade 11. We therefore estimate a series of IV, linear probability equations via two-stage least squares (2SLS) explaining

$$
M C_{s j t}=\rho+\rho_{1} \text { Share } M C_{j t}+\gamma X_{s j t}+\delta_{j}+\delta_{t}+\omega_{s j t}
$$

where $M C_{s j t}$ is an indicator for whether student $s$ in district $j$ and cohort $t$ completed Algebra II by $11^{\text {th }}$ grade. Share $M C_{j t}$ is the instrument, which records the proportion of students in a particular decile in district $j$ and cohort $t$ who completed Algebra II by $11^{\text {th }}$ grade. $X_{s j t}$ is a vector of student characteristics (including gender, race and ethnicity, eligibility for free or reducedprice meals, parental education levels, and $8^{\text {th }}$ grade end-of-grade test scores in math and reading). $\delta_{j}$ and $\delta_{t}$ are district and cohort fixed effects, respectively; ${ }^{15}$ and $\omega_{s j t}$ is a stochastic error term. We use predicted values from equation (1) in place of actual treatment status in our second-stage, decile-specific equations:

$$
Y_{s j t}=\alpha+\beta_{1} \widehat{M C}_{s j t}+\vartheta X_{s j t}+\theta_{j}+\theta_{t}+\varepsilon_{s j t}
$$

Here, $Y_{s j t}$ is the outcome of interest (such as enrollment in UNC-Chapel Hill, or the UNC public four-year system broadly), $X_{s j t}$ is the vector of student characteristics described above with the addition of a control to capture a student's accessibility to each institution in the UNC system (measured by the square-root of distance to the branch from the center of the student's home county). The coefficients $\theta_{j}$ and $\theta_{t}$ are district and cohort fixed effects, respectively; and $\varepsilon_{s j t}$ is a second, stochastic error term. The identifying assumption is that students in a particular decile who confronted large shares of high school students completing three math courses by $11^{\text {th }}$ grade

\footnotetext{
15 The indicators for the vectors of fixed effects are as follows: District group [Omitted variable: CharlotteMecklenburg] (Wake, Guilford, Cumberland, WS/Forsyth, Urban Mountain, Urban Piedmont, Urban Coastal, Rural Mountain, Rural Piedmont, Rural Coastal); Year [Omitted variable: 1999 cohort] (2000, 2001, 2002, 2003, 2004, 2005, 2006 cohort); Parental education level [Omitted variable: high school graduate] (did not finish high school, trade or business school graduate, community, technical or junior college graduate, four-year college graduate, graduate school degree); Gender [Omitted variable: male] (female); Race [Omitted variable: White] (AmericanIndian, Asian, Black, Hispanic, Multi-racial, Other). We present example first-stage results in Appendix Table A4.
} 
as a consequence of living in a particular district and being a member of a certain cohort differ relative to their same-decile counterparts who encountered smaller shares only in terms of their propensity to take Algebra II by the end of $11^{\text {th }}$ grade. ${ }^{16}$ Given this identifying assumption, $\beta_{1}$ in equation (2) gives the effect (for a student in a particular decile) of completing Algebra II by $11^{\text {th }}$ grade on the likelihood of outcome $Y_{i d c}$, compared to her counterpart who did not complete those three math courses by $11^{\text {th }}$ grade. We cluster standard errors at the district level to account for the nesting of students within schools and schools within districts.

VII. Effects on Patterns of College Enrollment

Our analysis of enrollment effects of the increase in minimum courses is necessarily limited because we have college enrollment information only for students who went to one of the public four-year colleges in North Carolina. Specifically, we need to interpret the results cautiously because we cannot capture postsecondary enrollment in private or out-of-state institutions. As a result, any increases we observe in the likelihood of enrollment in UNC institutions partially reflect a choice effect. That is, students were induced to take more math, allowing them admission into one of the state's four-year campuses rather than a community college or lower-quality, out-of-state institution.

Although the state's four-year universities share a common name, are governed by a single board, and are presided over by a single president, the reality on the ground is 15 separate institutions. No assessment of the effect of increasing the number of required math courses can ignore this reality. The more rigorous standard is likely to have had different ramifications across

\footnotetext{
${ }^{16}$ Another way to think about this identifying assumption is through the intuition of the exclusion restriction which, in this case, assumes that variation in decile-specific shares of students who take Algebra II by $11^{\text {th }}$ grade across districts and cohorts affects the (enrollment) outcomes of interest exclusively through an individual student's altered propensity to complete the three foundational math courses that culminate in Algebra II, and not through any other channel related to college enrollment. Conditioning on district fixed effects assuages potential concerns about static differences in districts' levels of college support and college-going cultures.
} 
those 15 separate institutions in part because of regional differences. To the extent that school districts responded differentially to the policy pronouncement, a branch campus that normally relies for most of its students on a laggard district in the mountains or the coast would have been disadvantaged in comparison to the universities that serve the more responsive urban districts.

Another reason to expect heterogeneous impacts across the 15 branches is that they tend to draw students from different parts of the ability distribution. To illustrate just how large these differences are, Table 2 reports, for the $19998^{\text {th }}$ grade cohort, the percentage distribution of entering students by $8^{\text {th }}$ grade end-of-grade math tests for each of the 15 institutions. Whereas 85\% of UNC-Chapel Hill's entering students from North Carolina scored in the top two deciles on that $8^{\text {th }}$ grade test, the comparable percentage at the median university was just $34 \%$, and it was less than $10 \%$ at three of the 15 .

For both groups of cohorts we estimated instrumental variable models for each decile and for each of the UNC system's 15 university branches, for a total of 300 different regressions. ${ }^{17}$ The 150 regressions estimated for the earlier, transitional cohorts, who were encouraged to take more math but were not punished if they did not (2000 and 2001, with 1999 as the pre-policy comparison cohort), each produced an estimate of the effect of increased rigor (increased probability of taking three math courses by $11^{\text {th }}$ grade). Those estimated coefficients are presented in Table 3a. A second set of regressions, shown in Table 3b, applies to the cohorts that felt the full force of the new minimum, the cohorts beginning with 2002. Consider first the pure effect of the increased math course-taking (in Table 3a). Virtually all of the estimated coefficients are positive, implying that, other things equal, completing Algebra II by $11^{\text {th }}$ grade raises the chance that a student will enroll in one of the state system's 15 branches. As an

\footnotetext{
${ }^{17}$ Complete sets of estimated coefficients for all explanatory variables are shown for three illustrative regressions in Appendix Table A3.
} 
example, a student in the $6^{\text {th }}$ decile who completes Algebra II by $11^{\text {th }}$ grade was 1.3 percentage points more likely to enroll at North Carolina State, the premier technical university in the public system, relative to her same-decile counterpart who failed to complete the courses that culminated in Algebra II. Broadly, increases in enrollment likelihoods due to math course-taking are largest for middle to upper-middle deciles of students. Table $3 \mathrm{~b}$ presents the corresponding set of estimated coefficients showing the combined effect of course-taking and the requirement for admission.

While the estimated coefficients in Tables $3 a$ and $3 b$ serve a guide as to the expected effect of completing Algebra II by $11^{\text {th }}$ grade on the likelihood of enrollment at a UNC institution for a typical student (in a specific decile), they provide less insight about predicted changes in the overall enrollment rate of students in a particular decile at a specific UNC institution as a consequence of changes in math course-taking patterns. Therefore, we combine our point estimates in Table 3 with observed changes in decile-by-district-specific shares of students who completed Algebra II by $11^{\text {th }}$ grade to translate the estimates for individuals to estimates of predicted impacts on enrollment rates by campus. .

Consider as an example the effect on the enrollment rate at East Carolina University (ECU) for students in the seventh math decile as a result of a 10 percentage point increase in the probability of finishing Algebra II by $11^{\text {th }}$ grade, as shown in Table 3a. Multiplying the increased probability of 0.1 by the coefficient $0.0323(3.2 \%)$ yields an increased probability of about 0.003 $(0.3 \%)$, or three tenths of one percentage point. Such effects can be more conveniently expressed as predicted changes in enrollment rates, by decile $(i)$ and branch campus $(k)$ :

$$
e 02_{i k}-e 99_{i k}=\beta_{i k}\left(\operatorname{AlgIIO2}_{i}-\operatorname{AlgII99}_{i}\right)
$$


where $A \operatorname{lgIIO2}{ }_{i}$ is a weighted average of the share of students in the 2002 cohort in decile $i$ who completed Algebra II by $11^{\text {th }}$ grade. This value can be computed for any decile and cohort across districts $(j)$ :

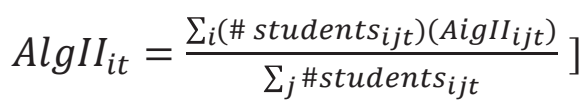

Once computed, we generate changes in this weighted share over the time period of interest and multiply by the corresponding coefficient $\left(\beta_{i k}\right)$, which denotes the effect on college-going at a particular campus.

Table $4 \mathrm{a}$ presents the predicted percentage point change in enrollment by campus due just to the induced increase in math course-taking. The largest predicted changes in rates $(0.2$ and larger) are shaded, highlighting a pattern of large implied increases clustering in deciles from which the bulk of each institution's students come.

Turning to the total effect of the new policy, Table $3 \mathrm{~b}$ presents the estimated effects of taking Algebra II by $11^{\text {th }}$ grade, and Table $4 \mathrm{~b}$ presents the corresponding predicted increases in enrollment by campus. These enrollment effects are generally much larger than those for the induced course-taking alone. For the example noted above, the effect in the seventh decile of enrolling at East Carolina is about twice as large, with a coefficient of 0.0478 . Table $4 \mathrm{~b}$ shows that this coefficient implies an increase in the enrollment rate of $0.4 \%$. By decile, the policy is predicted to boost enrollment rates the most for deciles 3-8, but these newly stimulated collegegoers were not evenly distributed across all branches. For the five historically black universities, the increases resulting from the tougher math standards are predicted to come from students residing in the lower deciles. ${ }^{18}$ For a middling institution like East Carolina, the biggest predicted increases are in the middle ranges. And for the top-ranked universities, Chapel Hill and NC

\footnotetext{
${ }^{18}$ As noted in Appendix Table A1, the five HBCUs in the University of North Carolina system are North Carolina A\&T, North Carolina Central, Elizabeth City State, Fayetteville State, and Winston-Salem State.
} 
State, the beefed-up math requirement is predicted to boost enrollment rates for high-scoring students. To the extent that the new policy encourages more top-aptitude students to take more math, the somewhat surprising predicted result is a bonanza for the flagship universities.

As a reality check, we computed the actual changes in enrollment rates to see how they compared to these predicted effects of the policy, shown in Table 5. The contrast is striking. The deciles of North Carolina students that actually saw the biggest increases were the four at the top, deciles 7-10, not the six near the middle. Evidently other forces were at work besides the decision to increase the minimum course requirement and, all told, these other forces were much larger than the effect of the increase in the minimum course requirement. That the policy's effect was overwhelmed by other influences should not obscure the fact that the policy did in fact exert a positive effect on college enrollment across the board.

VIII. Performance as UNC Students, Conditional on Enrollment

We now turn to the possible effects of the change in the minimum course requirement on students after they enroll in a UNC branch. We examined students' choice of major, their grades, and whether they graduate in four years, all conditional on having enrolled at one of the 15 campuses in the UNC system. We made no effort to account for possible bias due to selection between the UNC system and other alternatives, including not going to college. The question we pose here is, what was the effect on various outcomes, if any, of taking more math courses in high school? Consistent with our approach for enrollment patterns, we estimated models separately by decile. The estimated effects of taking Algebra II by $11^{\text {th }}$ grade are shown separately by decile in Table 6 . To bypass the added complication of accounting for selection among UNC branches, we make these assessments without accounting for which branch of the university a student attended. 
One possible outcome of requiring students to take more math in high school is to increase the number who will, in college, decide to major in a STEM field. To assess that possibility, we estimated one set of linear probability models explaining students' first declared major, and another set of models explaining their last declared major. ${ }^{19}$ The findings in Table 6 suggest that taking more math courses in high school may be associated with an increased propensity to major in a STEM field among some above-average-achieving students.

Additional estimates in column 3 of Table 6 suggest that taking more math courses in high school may also boost the final GPA of already high-performing students (i.e., those in deciles 7 and 8), though the magnitudes of these increases are quite large - potentially reflecting other difficult-to-measure differences between the populations of students who enroll in UNC with four high school math courses and those who do not. In only one decile is taking more math courses associate $4 \mathrm{~d}$ with higher rates of graduation, decile 8 . Because they show up as significant in only a few deciles, these conditional estimates ought to be taken with a grain of salt. But, because different outcomes cluster in the same two deciles, 7 and 8 , the patterns are worthy of note because they apply to students at the same achievement level.

\section{Conclusion}

In 2000 the state of North Carolina announced that it would increase the minimum number of high school math courses students would need to be eligible for admission to any four-year public college in the state. This policy change could have had three effects. First, it could have led to an increase in the number of math courses students take in high school.

\footnotetext{
${ }^{19}$ First, we determine the earliest-declared major via CIP codes. That is, we use his available CIP code applying to the earliest class level for his earliest-declared major field of study. In our sample, there were 130,588 students whose CIP codes were available for at least one class level. Among these students, the earliest class level that CIP code is available is first year, for $61 \%$ of the students; second year, for $15 \%$ of the students; third year, for $21 \%$ of the students; and fourth year, for $3 \%$ of the students.
} 
Second, it could have influenced patterns of enrollment across the various branch campuses in the University of North Carolina system. Third, by strengthening the math preparation of students, it could have affected students' choices of major or improved their performance in college. We examine each of these three questions in this paper, using student-level administrative data. Because we do not have information on all of the courses students took in high school, we adopt as a proxy for the ability and intention of taking four courses whether students had taken Algebra II by $11^{\text {th }}$ grade.

Because the state allowed schools two years to prepare for this new requirement, two cohorts of high school students were made aware of the state's heightened expectations without actually facing the prospect of being refused admission if they did not take the required four math courses. For these cohorts, we can observe the pure effect of increased math course-taking in high school, unaffected by the threat of being refused admission. Subsequent cohorts experienced both the effect of increased course-taking and the threat of sanction for failing to meet the new standard.

In answer to the first question, we find that students did take more math courses in high school following the state's announcement of a new standard. The increase was not uniform, however. For example, even before the new policy was announced, many students with high math aptitude had already been taking enough math in high school to have finished Algebra II by $11^{\text {th }}$ grade. To be sure, the share of students taking Algebra II by $11^{\text {th }}$ grade was higher in some districts than in others, even for students with similar math aptitude. Indeed, variations across districts such as these allow us to address questions two and three. These variations created a natural experiment in which students across the state were exposed to math instruction regimes of varying rigor, simply as a function of where they lived and when they had been born. As for 
the increases across the state in the number of students exposed to this increased rigor, the timing and rapidity of the increases suggest that the state's announcement was the cause. But we cannot know for sure whether other influences, such as discussions among education experts across the country, also had a hand in these increases.

To address the second question, whether the increases in math-taking and the subsequent admissions requirement affected patterns of enrollment, we estimated a series of IV models predicting enrollment at particular branch campuses as a function of whether a student had taken Algebra II by $11^{\text {th }}$ grade. These models imply that the policy led to increases in enrollment rates, but these increases were not uniform. Rather, the largest increases were observed in deciles of student achievement from which branch universities were already drawing the bulk of their students. Thus, for the state's top universities, the policy did not have the effect of opening the door to large numbers of students at lower achievement levels who had previously not applied or not been admitted because of their high schools' limited math offerings. It did, however, mean that newer cohorts of entering students had better math training than those of the recent past.

In answer to the third question, whether the policy had effects on students once in a UNC institution, we found very little of significance. We found that increases in math were associated for only one decile with an increase in the chance a student would declare and stick with a STEM major. For that decile, the $7^{\text {th }}$, we also observed a positive association with GPA, and for deciles 8 and higher, although the errors associated with those estimates are large. Finally, we observed a positive association between increased math-taking and graduation for one decile, the $8^{\text {th }}$.

In North Carolina's decision to increase minimum course requirements in math for admission to the University of North Carolina system, we encounter a policy with possible effects on students both before and after high school graduation. Owing to this dual nature, the 
policy has the potential to have quite far-reaching effects. Although our evidence is circumstantial, our assessment suggests that the pre-graduate effects are the more important. To back up that claim, we point to the sizable increases in the number of high school students who had taken Algebra II by the time they had finished $11^{\text {th }}$ grade. Statewide, the proportion of students who had achieved this benchmark rose by nearly 8 percentage points in the span of only three years. For students in the bottom half of the achievement distribution, the increase was even more, on the order of 11 percentage points. For any single student, achieving this benchmark was an important accomplishment because it made possible taking one additional math course in the senior year, signaling both the ability and the intention of taking a total of four math courses in high school. It is difficult to imagine another policy that could have been as effective in so short a time in raising exposure to math instruction in high school.

The post-graduation effects of the policy are less straightforward and probably are less important. By increasing math readiness, the policy itself increased the probability that students would enroll in the state's public four-year universities. But the effect of the policy was small in relation to other influences on enrollment, meaning that the policy did not lead to large changes in the composition of entering classes at the state's public universities. It did lead to entering classes with stronger math, however, and this result alone might justify the policy. Once in college, however, the students touched by this policy showed little statistically significant improvement in the metrics available to us, such as graduation. Nonetheless, this would appear to be a question worth pursuing further, given the increase in math courses students had taken before enrolling. 


\section{References}

Allensworth, E., T. Nomi, N. Montgomery, and V.E. Lee (2009). College Preparatory Curriculum for all: Academic Consequences of Requiring Algebra and English I for ninth graders in Chicago. Educational Evaluation and Policy Analysis, 31, 367-391.

Clotfelter, C. T., Ladd, H. F., \& Vigdor, J. L. (2003). Segregation and Resegregation in North Carolina's Public School Classrooms. North Carolina Law Review, 81, 1463-1511.

Clotfelter, C. T., Ladd, H. F., \& Vigdor, J. L. (2015). The aftermath of accelerating Algebra: Evidence from district policy initiatives. Journal of Human Resources, 50, 159-188.

Cortes, K., Goodman, J., \& Nomi, T. (2015). Intensive math instruction and educational attainment: Long-run impacts of double-dose algebra. Journal of Human Resources, 50, 108-158.

Goodman, J. (2012). The labor market division: Returns to compulsory math coursework. Harvard Kennedy School Faculty Research Working Paper Series, RWP12-RW032. Access: http://scholar.harvard.edu/files/joshuagoodman/files/rwp12032 goodman.pdf?m=1375889148

Long, M. C., Conger, D., Iatarola, P. (2012). Effects of high school course-taking on secondary and postsecondary success. American Educational Research Journal, 49(2), 285-322.

Long, M. C., Iatarola, P., Conger, D. (2009). Explaining gaps in readiness for college-level math: The role of high school courses. Education Finance and Policy, 4(1), 1-33.

Nomi, T. (2012). Double dose algebra as an alternative strategy to remediation: Effects of students' academic outcomes. Journal of Research on Educational Effectiveness, 2, 111148.

Nomi, T., \& Allensworth, E. (2009). Sorting and supporting: Why double-dose algebra leads to better test scores but more course failure. American Educational Research Journal, 50, 756-788.

Rose, H., \& Betts, J. R. (2001). "Math Matters: The Link Between High School Curriculum, College Graduation, and Earnings," Public Policy Institute of California.

Schoenfeld, A. (1995) "Report of Working Group 1." in C. Lacampagne, W. Blair, and J. Kaput (eds.) The Algebra Initiative Colloquium: Papers Presented at a Conference on Reform in Algebra. Washington: U.S. Department of Education, Office of Educational Research and Improvement. 


\section{Figures and Tables}

Figure 1. Percentage of Students Who Took Algebra II by $11^{\text {th }}$ Grade, by $8^{\text {th }}$ Grade Cohort, Selected Math Deciles, State of North Carolina

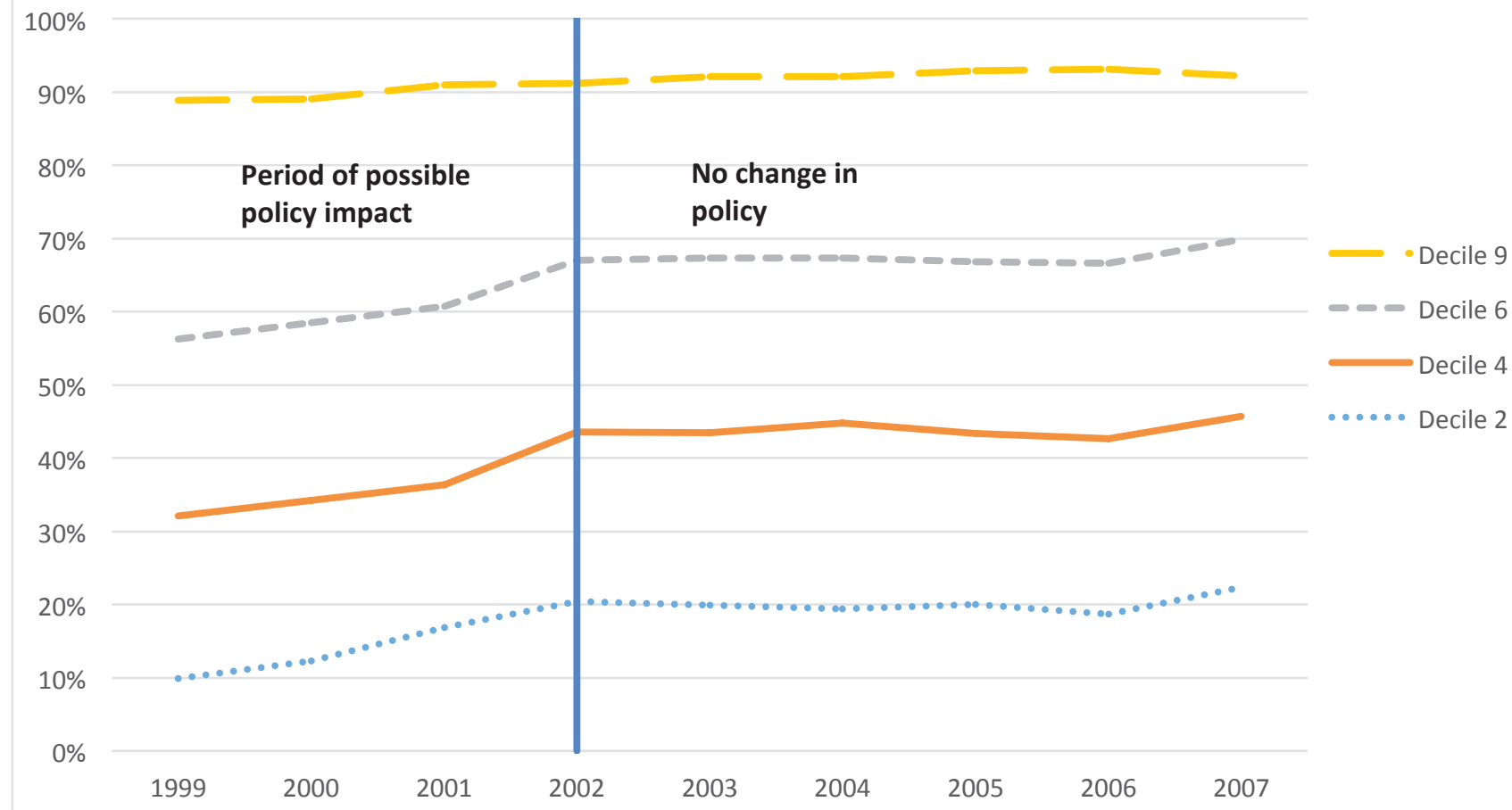

Notes: Data come from the North Carolina Education Research Data Center (NCERDC), end-of-year and end-ofcourse (EOC) assessments. 
Figure 2. Percentage of Students Who Took Algebra II by $11^{\text {th }}$ Grade: 1999 and $20028^{\text {th }}$ Grade Cohorts, Decile 2

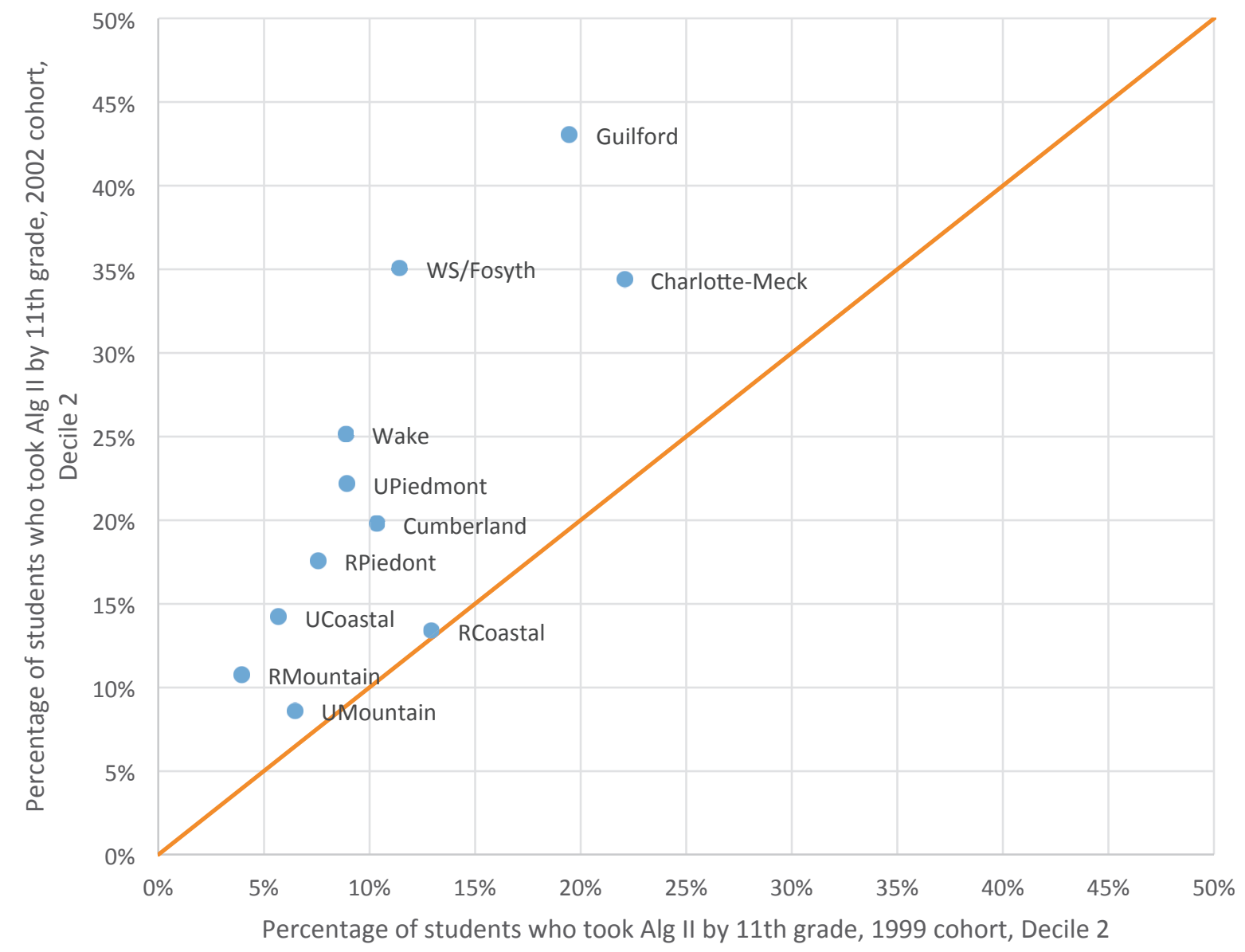

Note: In addition to the state's five largest districts, percentages are recorded for six district groups: rural coastal, rural Piedmont, rural mountain, urban coastal, urban Piedmont, and urban mountain. Students were divided into deciles based on their $8^{\text {th }}$ grade math end-of-year test scores. Cohorts were defined according to the year students finished $8^{\text {th }}$ grade. 
Figure 3. Percentage of Students Who Took Algebra II by $11^{\text {th }}$ Grade: 1999 and $20028^{\text {th }}$ Grade Cohorts, Decile 4

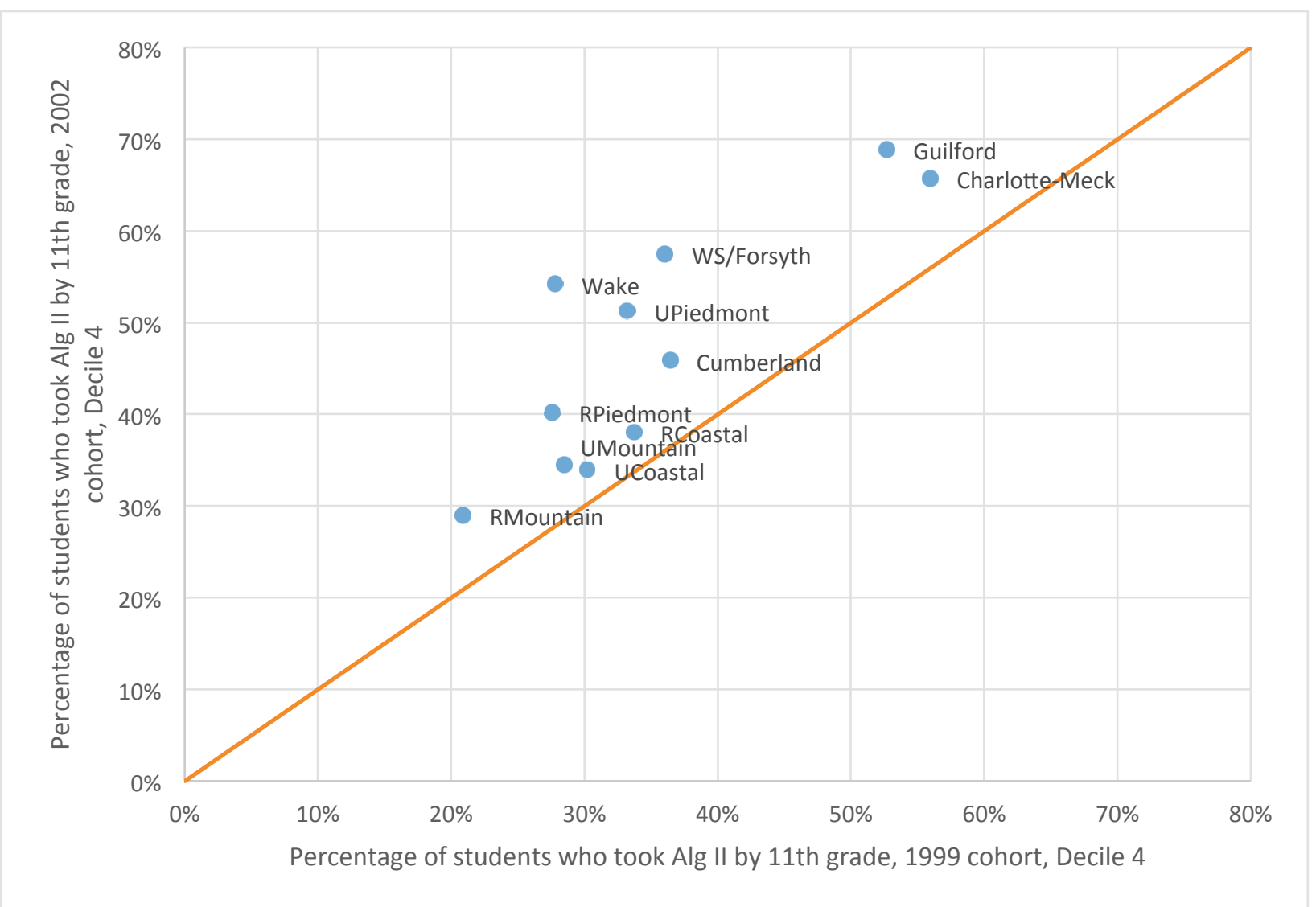

Note: In addition to the state's five largest districts, percentages are recorded for six district groups: rural coastal, rural Piedmont, rural mountain, urban coastal, urban Piedmont, and urban mountain. Students were divided into deciles based on their $8^{\text {th }}$ grade math end-of-year test scores. Cohorts were defined according to the year students finished $8^{\text {th }}$ grade. 
Figure 4. Percentage of Students Who Took Algebra II by $11^{\text {th }}$ Grade: 1999 and $20028^{\text {th }}$ Grade Cohorts, Decile 6

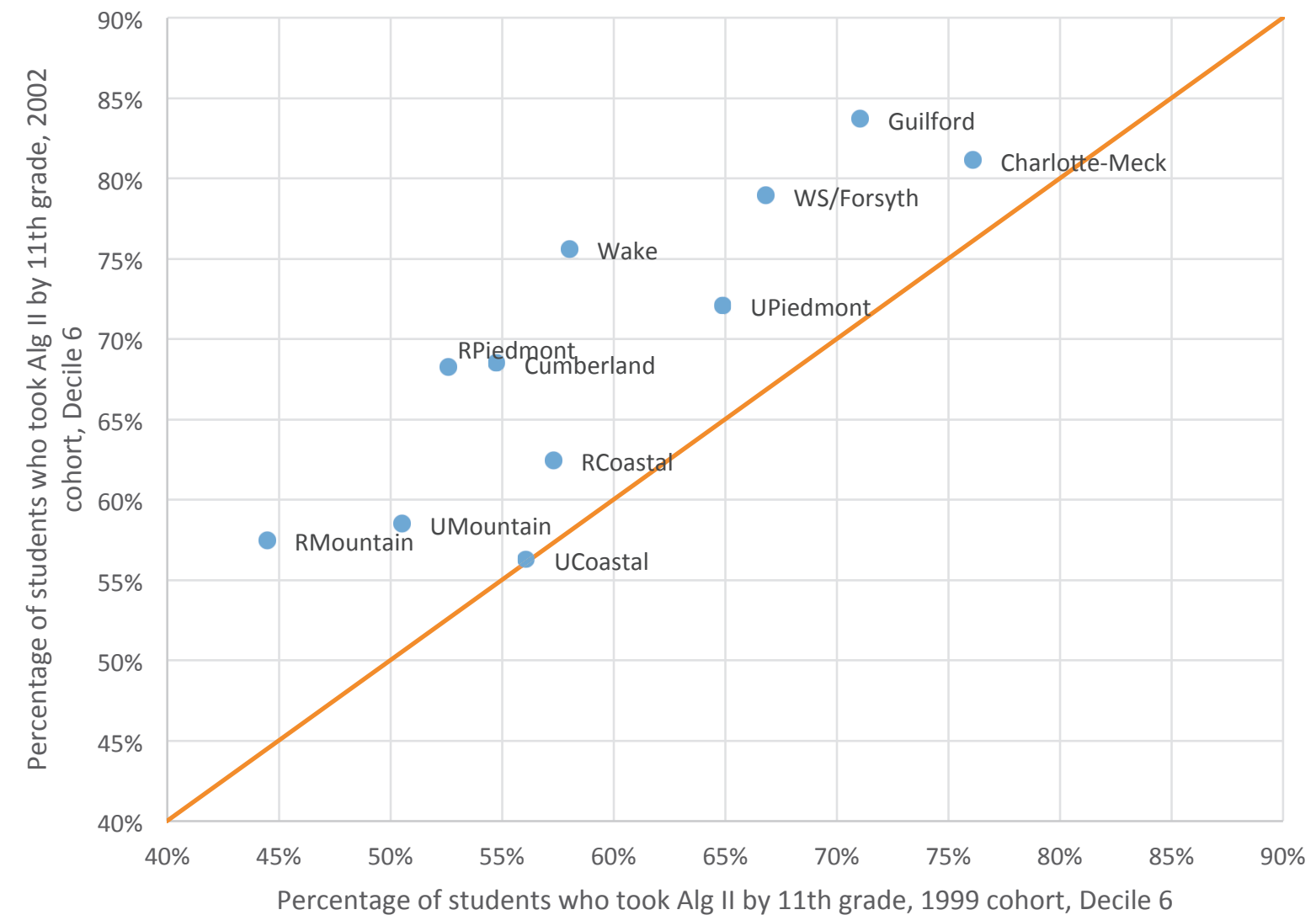

Note: In addition to the state's five largest districts, percentages are recorded for six district groups: rural coastal, rural Piedmont, rural mountain, urban coastal, urban Piedmont, and urban mountain. Students were divided into deciles based on their $8^{\text {th }}$ grade math end-of-year test scores. Cohorts were defined according to the year students finished $8^{\text {th }}$ grade. 
Figure 5. Percentage of Students Who Took Algebra II by $11^{\text {th }}$ Grade: 1999 and $20028^{\text {th }}$ Grade Cohorts, Decile 9

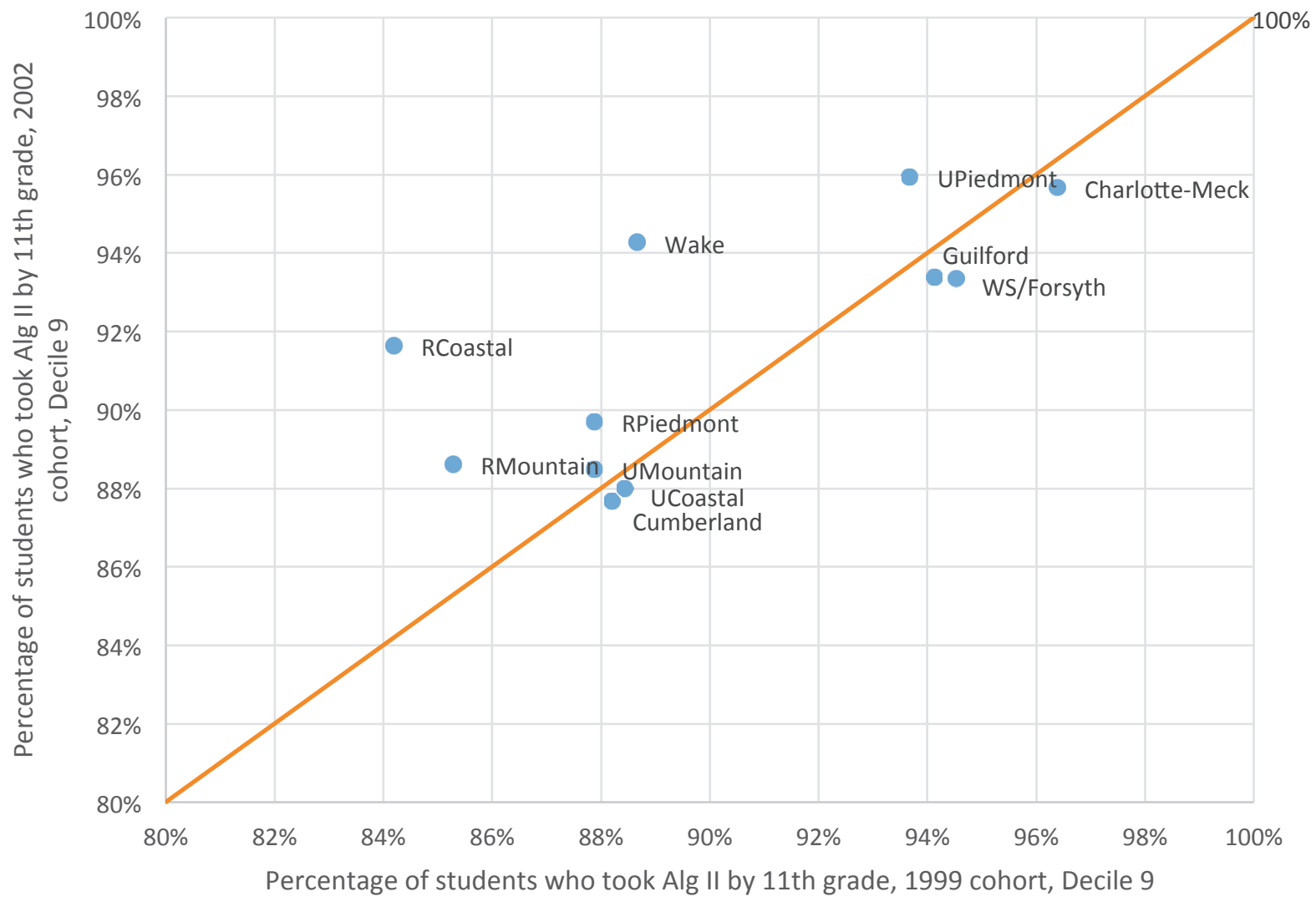

Note: In addition to the state's five largest districts, percentages are recorded for six district groups: rural coastal, rural Piedmont, rural mountain, urban coastal, urban Piedmont, and urban mountain. Students were divided into deciles based on their $8^{\text {th }}$ grade math end-of-year test scores. Cohorts were defined according to the year students finished $8^{\text {th }}$ grade. 


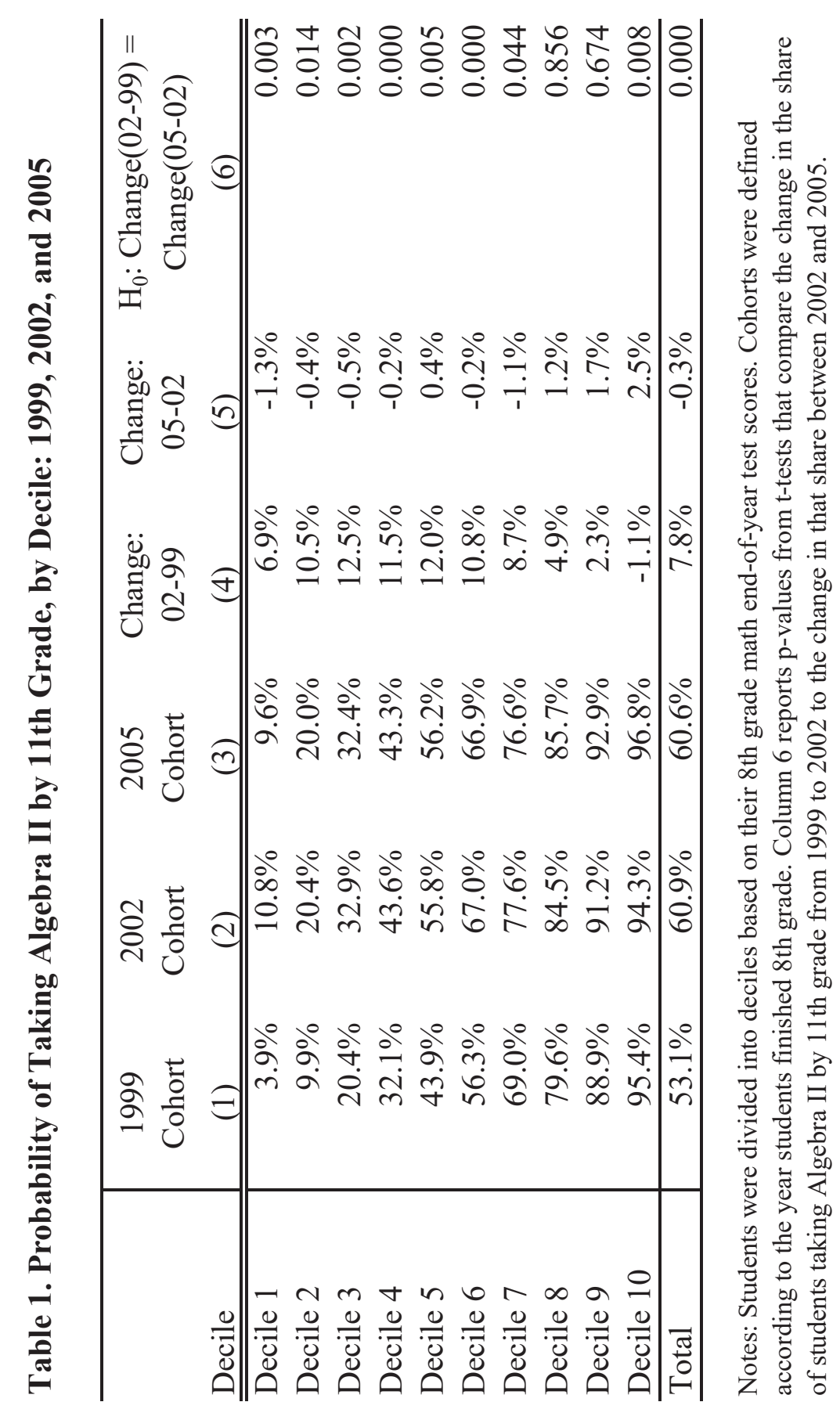




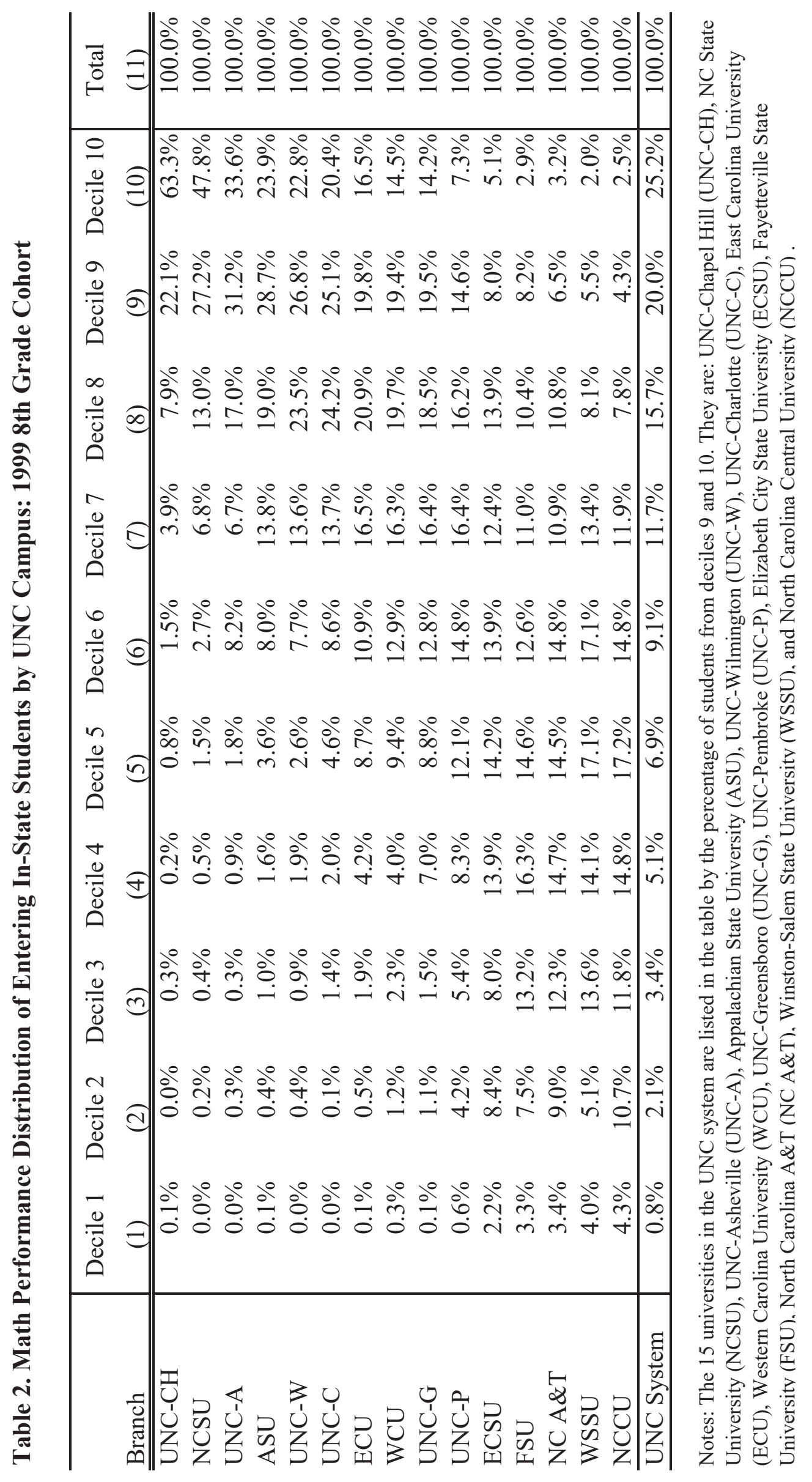




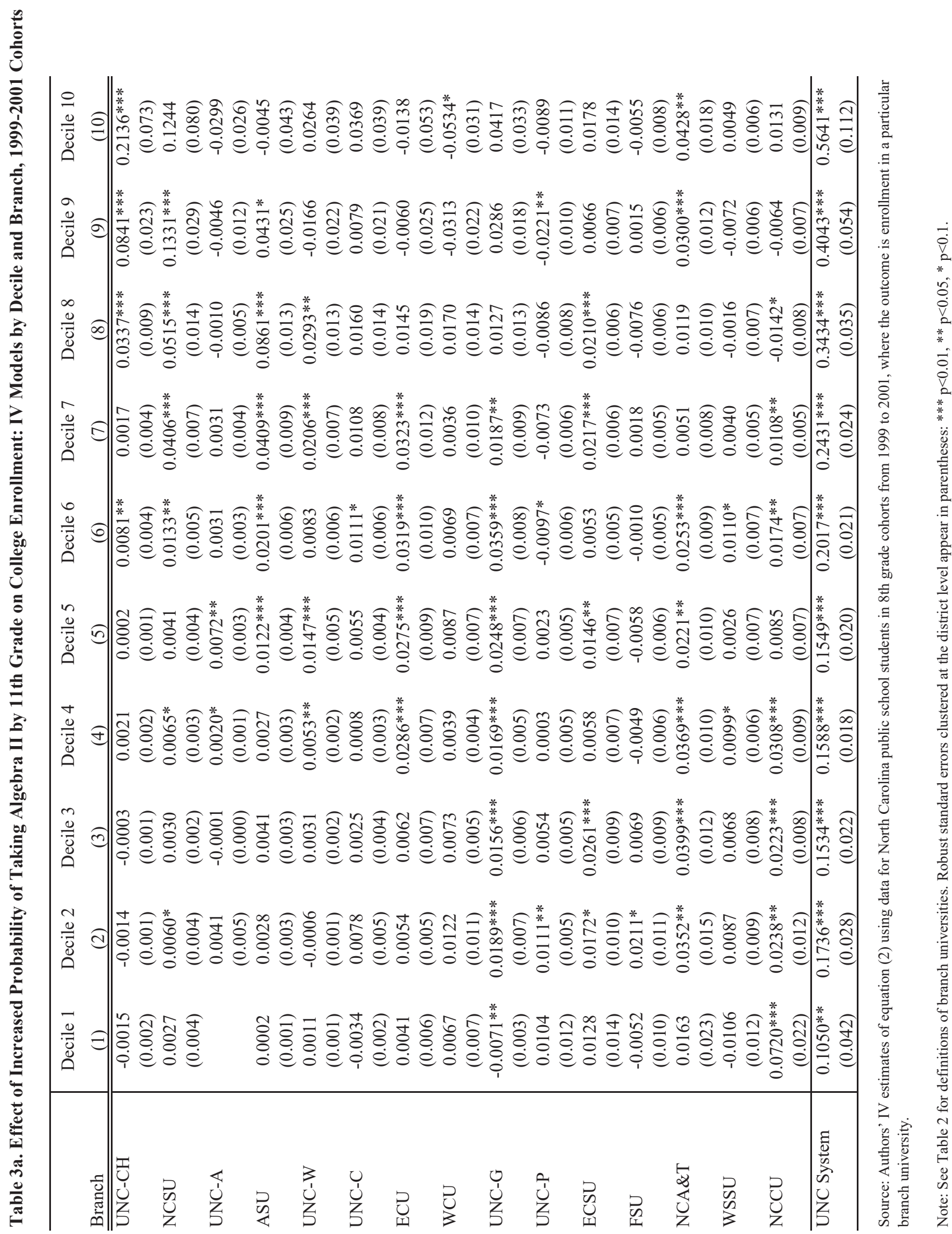




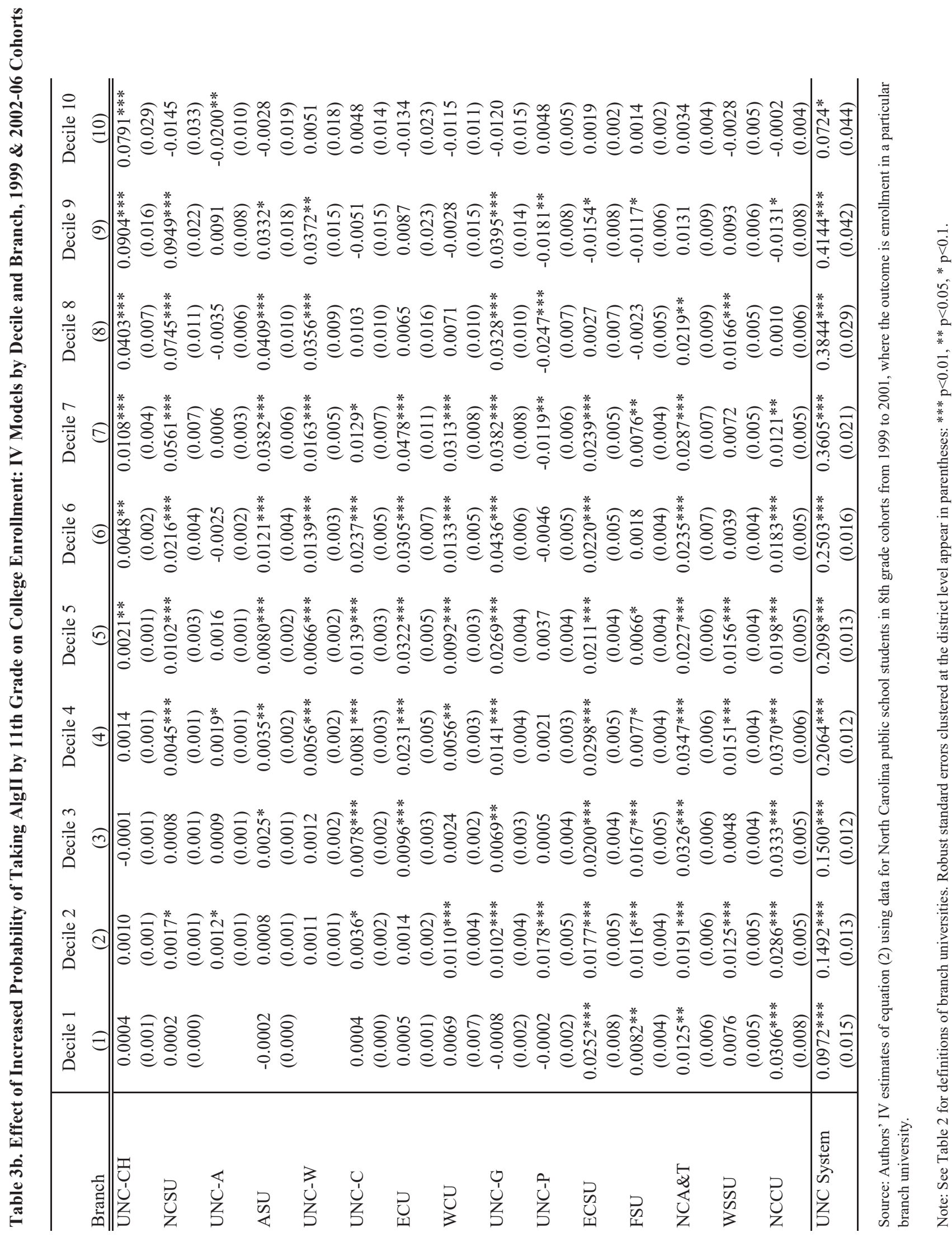




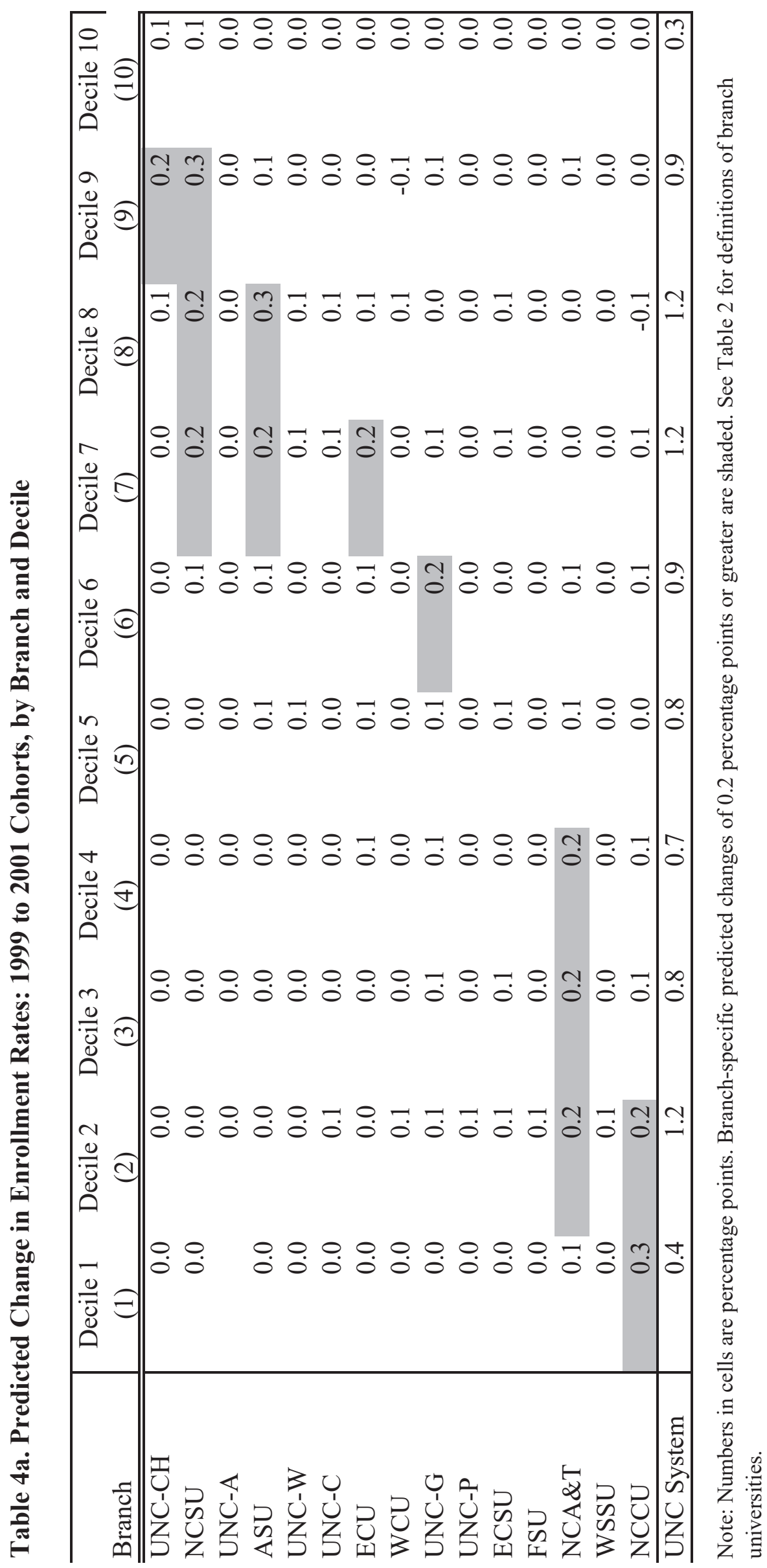




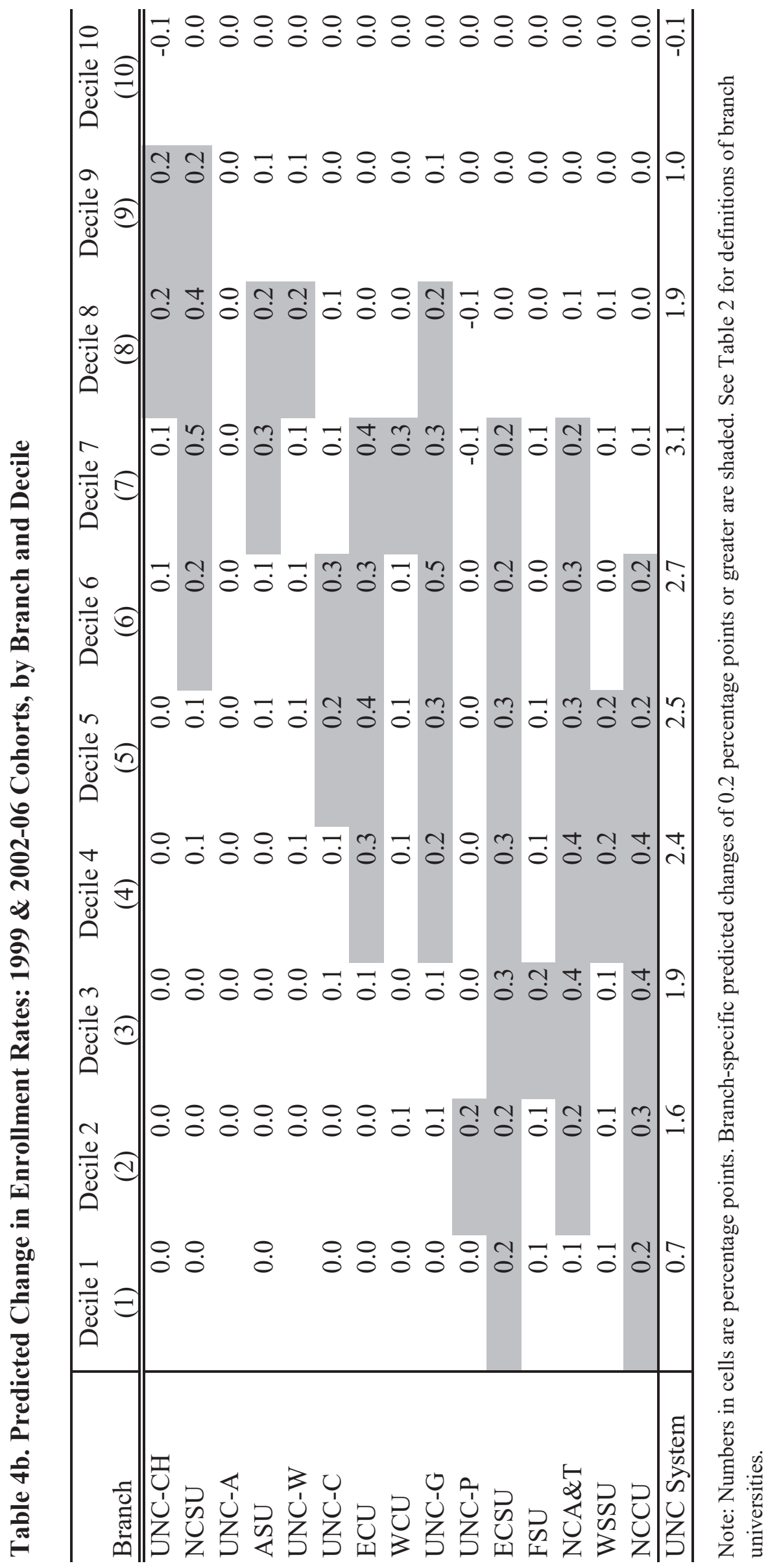




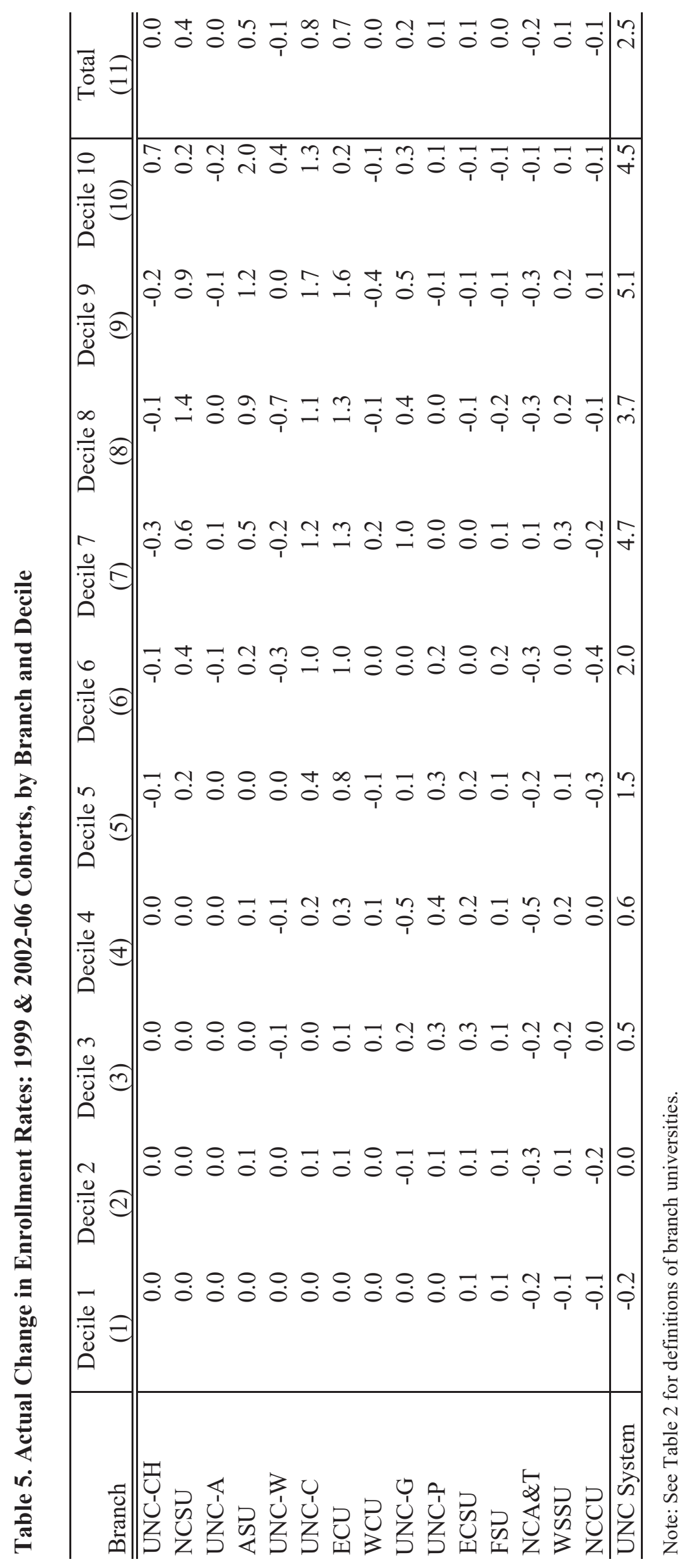


Table 6. Effect of Increased Math Course-taking on Post-Enrollment Choices and Outcomes: STEM Major, GPA, and Graduation in Four Years, by Decile, Based on Models Estimated for 1999 to 2001 Cohorts

\begin{tabular}{|c|c|c|c|c|}
\hline & \multicolumn{2}{|c|}{ Major in STEM } & \multirow{2}{*}{ Final GPA } & \multirow{2}{*}{$\begin{array}{c}\text { Graduation in } \\
4 \text { Years }\end{array}$} \\
\hline & Initial & Final & & \\
\hline UNC Enrollee in... & (1) & (2) & (3) & (4) \\
\hline$\overline{\text { Decile } 1}$ & $\begin{array}{l}-0.2457 \\
0.208)\end{array}$ & $\begin{array}{l}-0.1851 \\
(0.206)\end{array}$ & $\begin{array}{l}-0.3329 \\
(0.384)\end{array}$ & $\begin{array}{l}0.3553 \\
(0.228)\end{array}$ \\
\hline Observation & 318 & 318 & 365 & 380 \\
\hline Mean & 0.3068 & 0.2566 & 2.0348 & 0.1744 \\
\hline Decile 2 & $\begin{array}{l}0.0889 \\
(0.145)\end{array}$ & $\begin{array}{l}-0.0064 \\
(0.132)\end{array}$ & $\begin{array}{l}-0.0195 \\
(0.236)\end{array}$ & $\begin{array}{l}0.0724 \\
(0.128)\end{array}$ \\
\hline Observation & 823 & 823 & 980 & 1,011 \\
\hline Mean & 0.3325 & 0.2613 & 2.0796 & 0.1957 \\
\hline Decile 3 & $\begin{array}{l}-0.1346 \\
(0.119)\end{array}$ & $\begin{array}{l}-0.1719 \\
(0.117)\end{array}$ & $\begin{array}{l}0.0815 \\
(0.190)\end{array}$ & $\begin{array}{l}0.0301 \\
(0.095)\end{array}$ \\
\hline Observation & 1,484 & 1,484 & 1,677 & 1,729 \\
\hline Mean & 0.3202 & 0.2701 & 2.175 & 0.2308 \\
\hline Decile 4 & $\begin{array}{l}0.0609 \\
(0.098)\end{array}$ & $\begin{array}{l}0.0546 \\
(0.093)\end{array}$ & $\begin{array}{l}0.0776 \\
(0.180)\end{array}$ & $\begin{array}{l}0.0370 \\
(0.086)\end{array}$ \\
\hline Observation & 2,199 & 2,199 & 2,501 & 2,575 \\
\hline Mean & 0.3232 & 0.2598 & 2.2324 & 0.266 \\
\hline Decile 5 & $\begin{array}{l}0.0493 \\
(0.120)\end{array}$ & $\begin{array}{l}0.0980 \\
(0.113)\end{array}$ & $\begin{array}{l}0.0445 \\
(0.196)\end{array}$ & $\begin{array}{l}0.0125 \\
(0.104)\end{array}$ \\
\hline Observation & 3,034 & 3,034 & 3,497 & 3,588 \\
\hline Mean & 0.3404 & 0.2905 & 2.3077 & 0.2939 \\
\hline Decile 6 & $\begin{array}{c}0.3096^{* *} \\
(0.140)\end{array}$ & $\begin{array}{l}0.2014 \\
(0.131)\end{array}$ & $\begin{array}{l}0.3157 \\
(0.214)\end{array}$ & $\begin{array}{l}0.1289 \\
(0.115)\end{array}$ \\
\hline Observation & 4,022 & 4,022 & 4,665 & 4,763 \\
\hline Mean & 0.3211 & 0.2707 & 2.4093 & 0.3379 \\
\hline Decile 7 & $\begin{array}{c}0.3265^{* *} \\
(0.158)\end{array}$ & $\begin{array}{c}0.4545^{* * *} \\
(0.152)\end{array}$ & $\begin{array}{c}0.6810^{* *} \\
(0.280)\end{array}$ & $\begin{array}{l}0.0722 \\
(0.143)\end{array}$ \\
\hline Observation & 5,258 & 5,258 & 6,131 & 6,250 \\
\hline Mean & 0.3493 & 0.2948 & 2.479 & 0.3754 \\
\hline Decile 8 & $\begin{array}{l}0.3831 \\
(0.246)\end{array}$ & $\begin{array}{l}0.3033 \\
(0.232)\end{array}$ & $\begin{array}{c}0.8084^{* *} \\
(0.387)\end{array}$ & $\begin{array}{c}0.5335^{* *} \\
(0.214)\end{array}$ \\
\hline Observation & 7,202 & 7,202 & 8,213 & 8,331 \\
\hline Mean & 0.3656 & 0.325 & 2.6093 & 0.4425 \\
\hline Decile 9 & $\begin{array}{l}0.3091 \\
(0.373)\end{array}$ & $\begin{array}{l}-0.0326 \\
(0.359)\end{array}$ & $\begin{array}{l}0.9402^{*} \\
(0.567)\end{array}$ & $\begin{array}{l}0.1842 \\
(0.313)\end{array}$ \\
\hline Observation & 9,137 & 9,137 & 10,258 & 10,381 \\
\hline Mean & 0.3925 & 0.3497 & 2.7255 & 0.4929 \\
\hline Decile 10 & $\begin{array}{l}0.9580 \\
(0.662)\end{array}$ & $\begin{array}{l}0.4124 \\
(0.633)\end{array}$ & $\begin{array}{l}1.7561^{*} \\
(0.979)\end{array}$ & $\begin{array}{l}0.4399 \\
(0.558)\end{array}$ \\
\hline Observation & 11,818 & 11,818 & 12,806 & 12,933 \\
\hline Mean & 0.4921 & 0.4535 & 2.9702 & 0.5916 \\
\hline
\end{tabular}

Notes: Authors' IV estimates of equation (2) using data for North Carolina public school students in 8th grade cohorts from 1999 to 2001 who enrolled in the University of North Carolina. Robust standard errors clustered at the district level appear in parentheses: $* * * \mathrm{p}<0.01, * * \mathrm{p}<0.05, * \mathrm{p}<0.1$. 


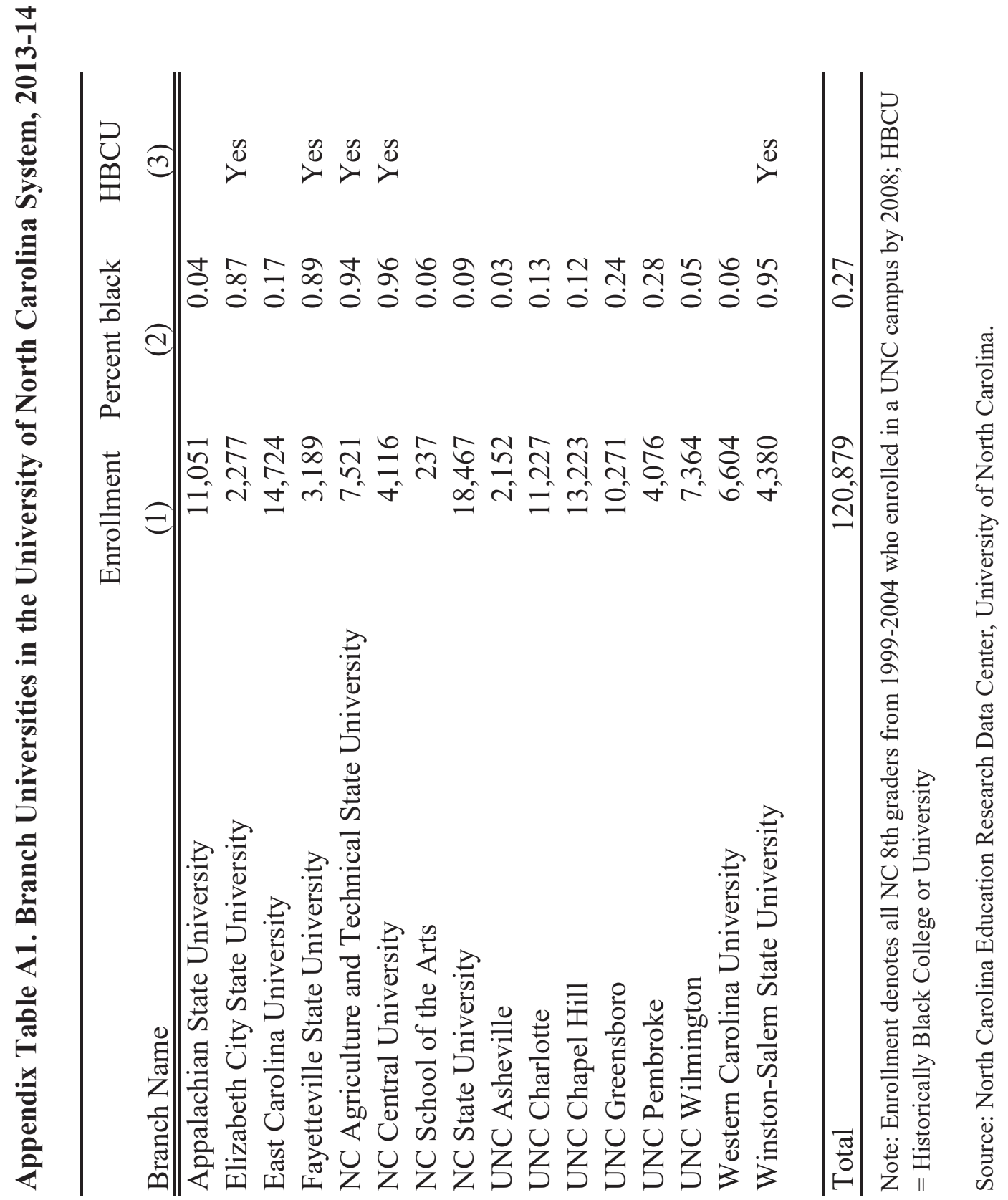




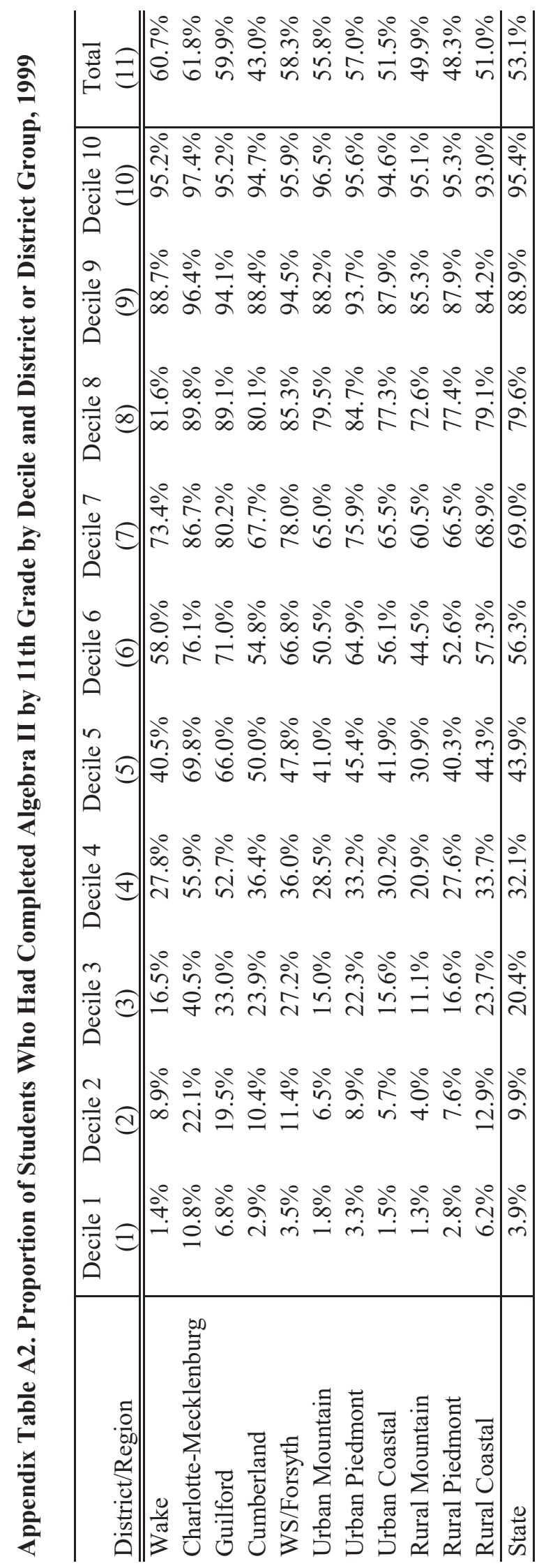




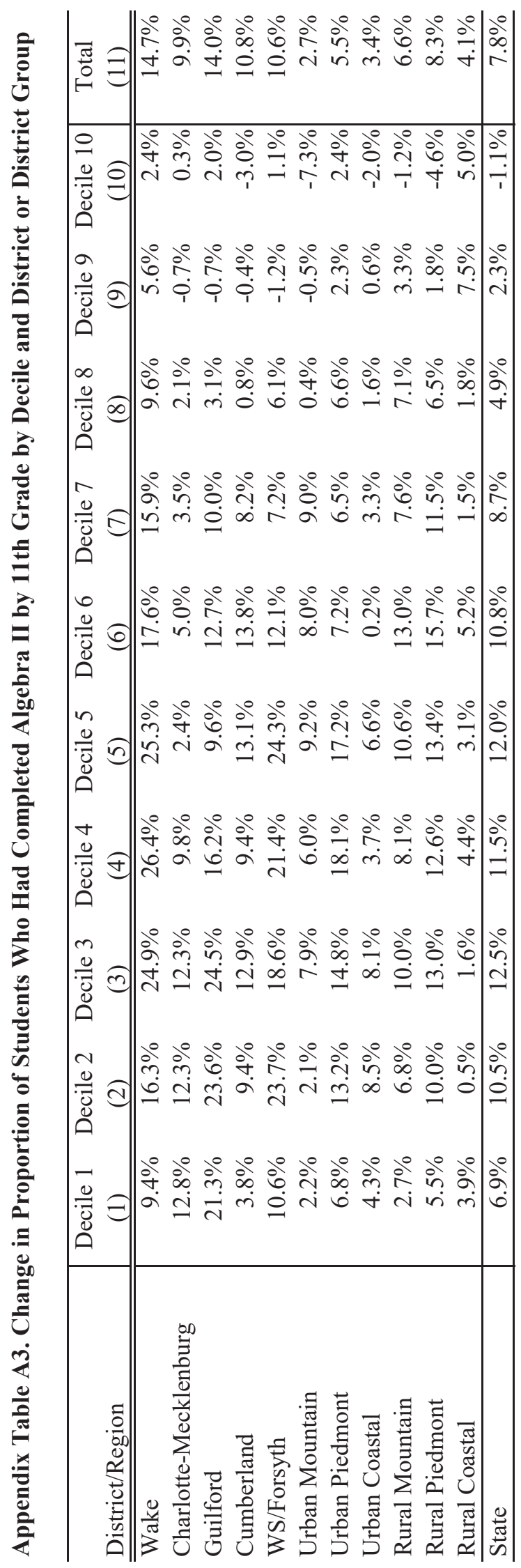




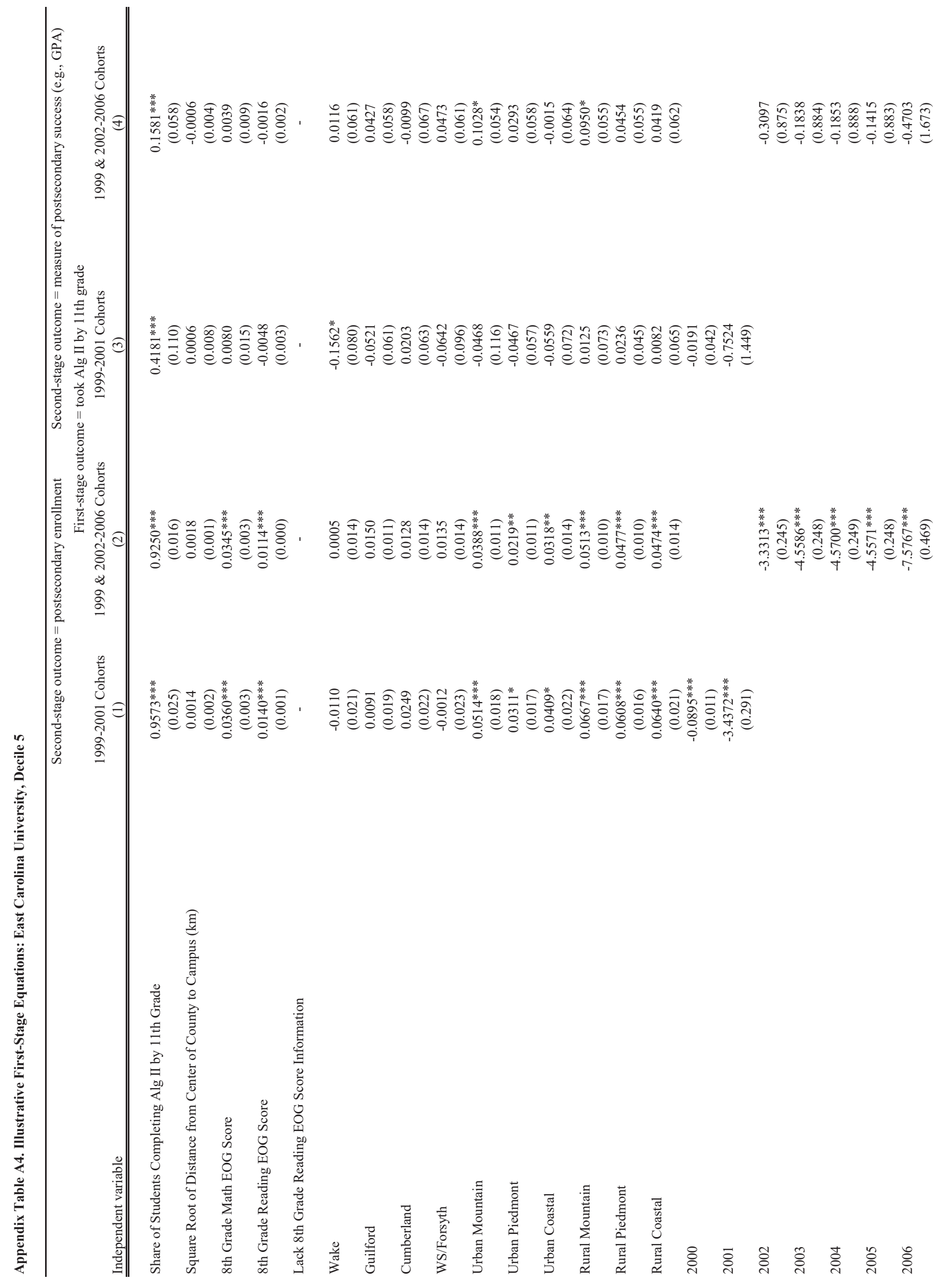




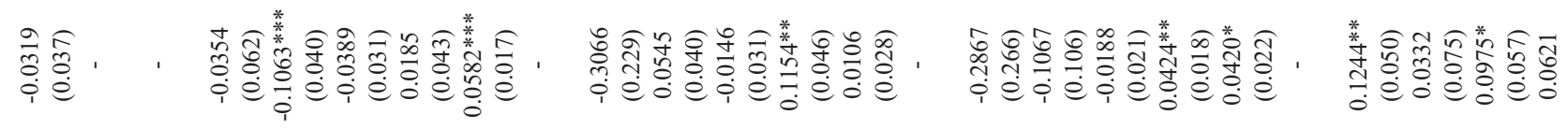

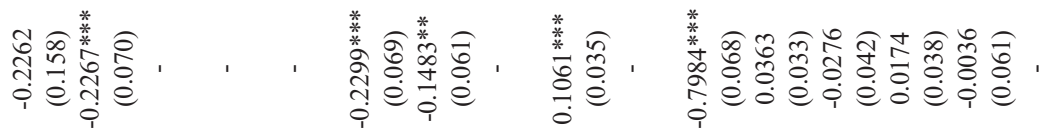

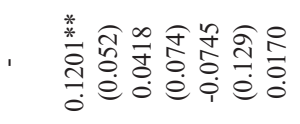

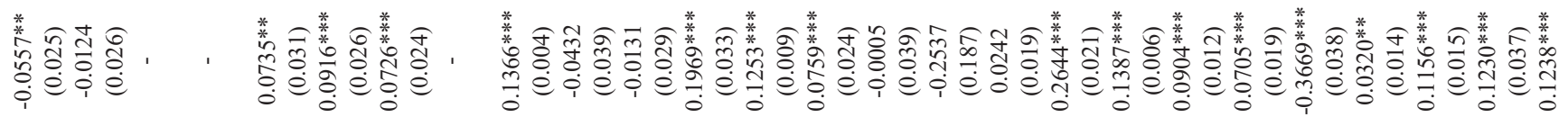

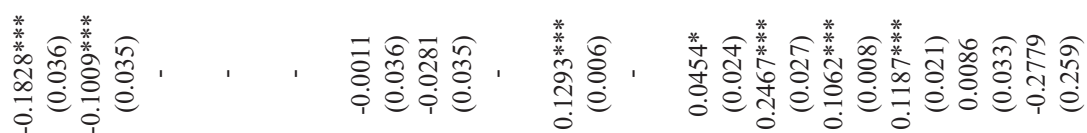
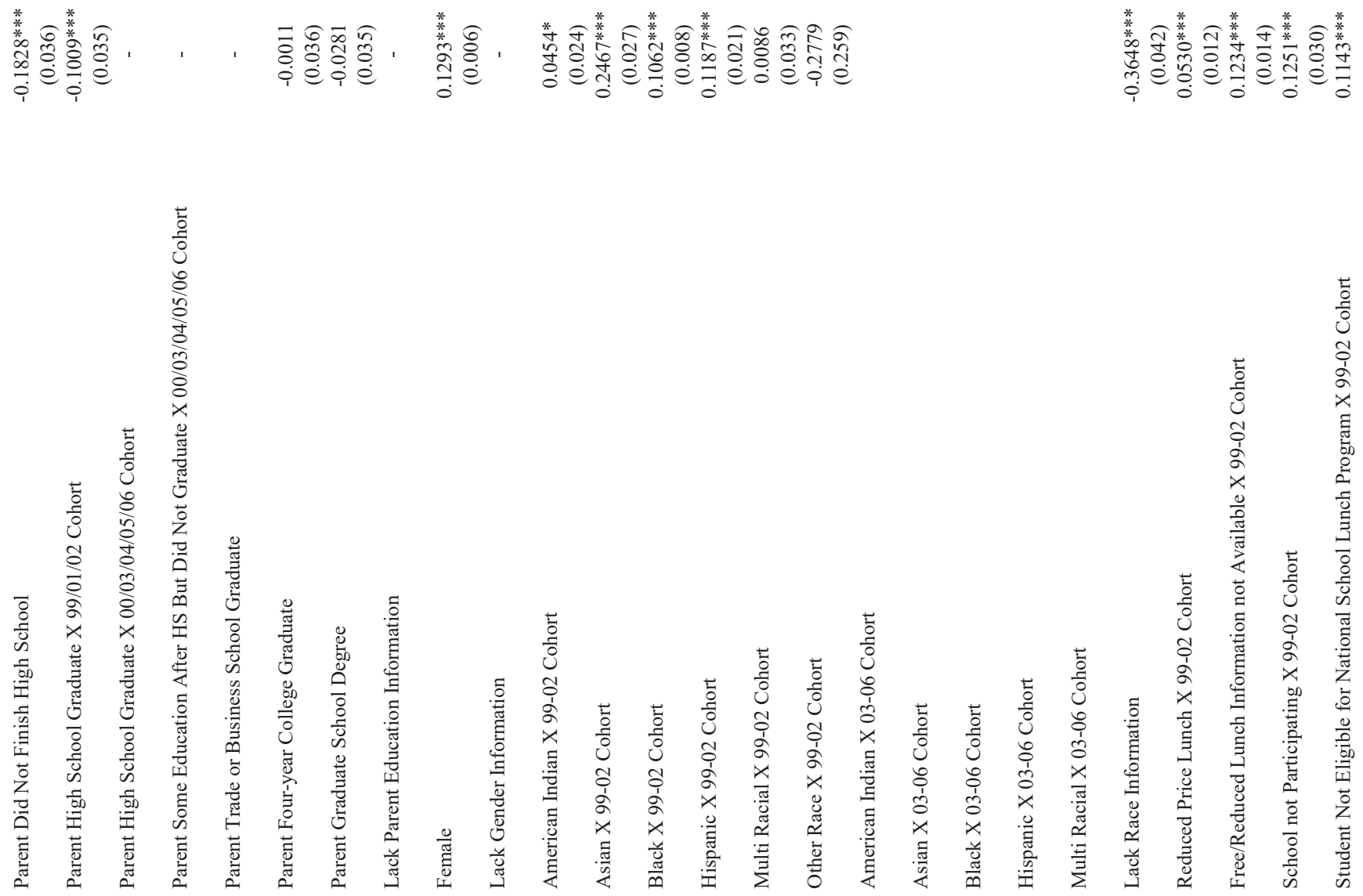


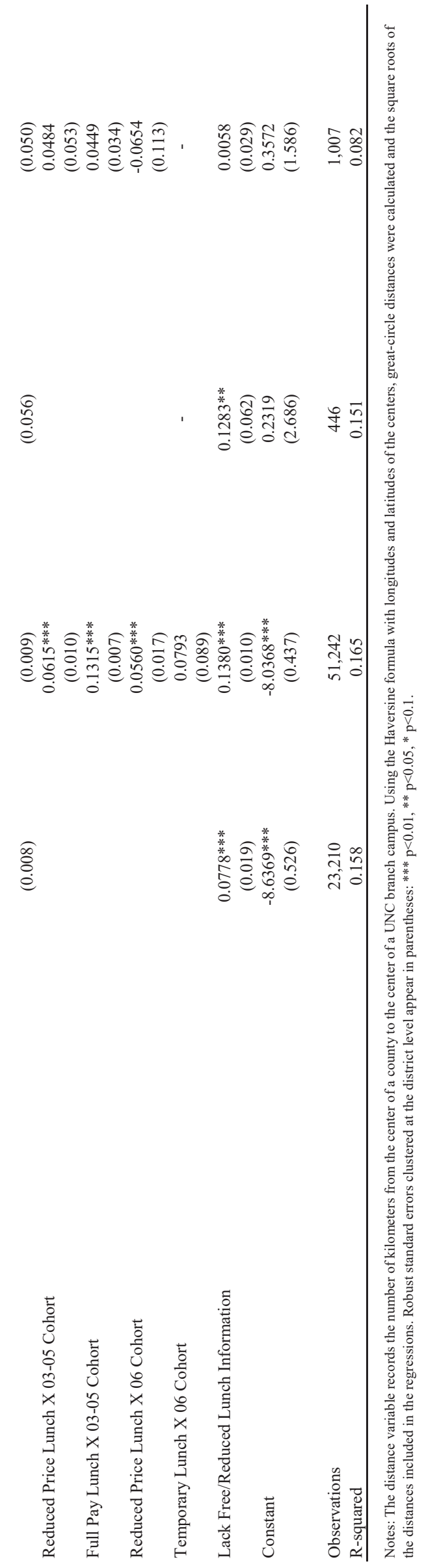




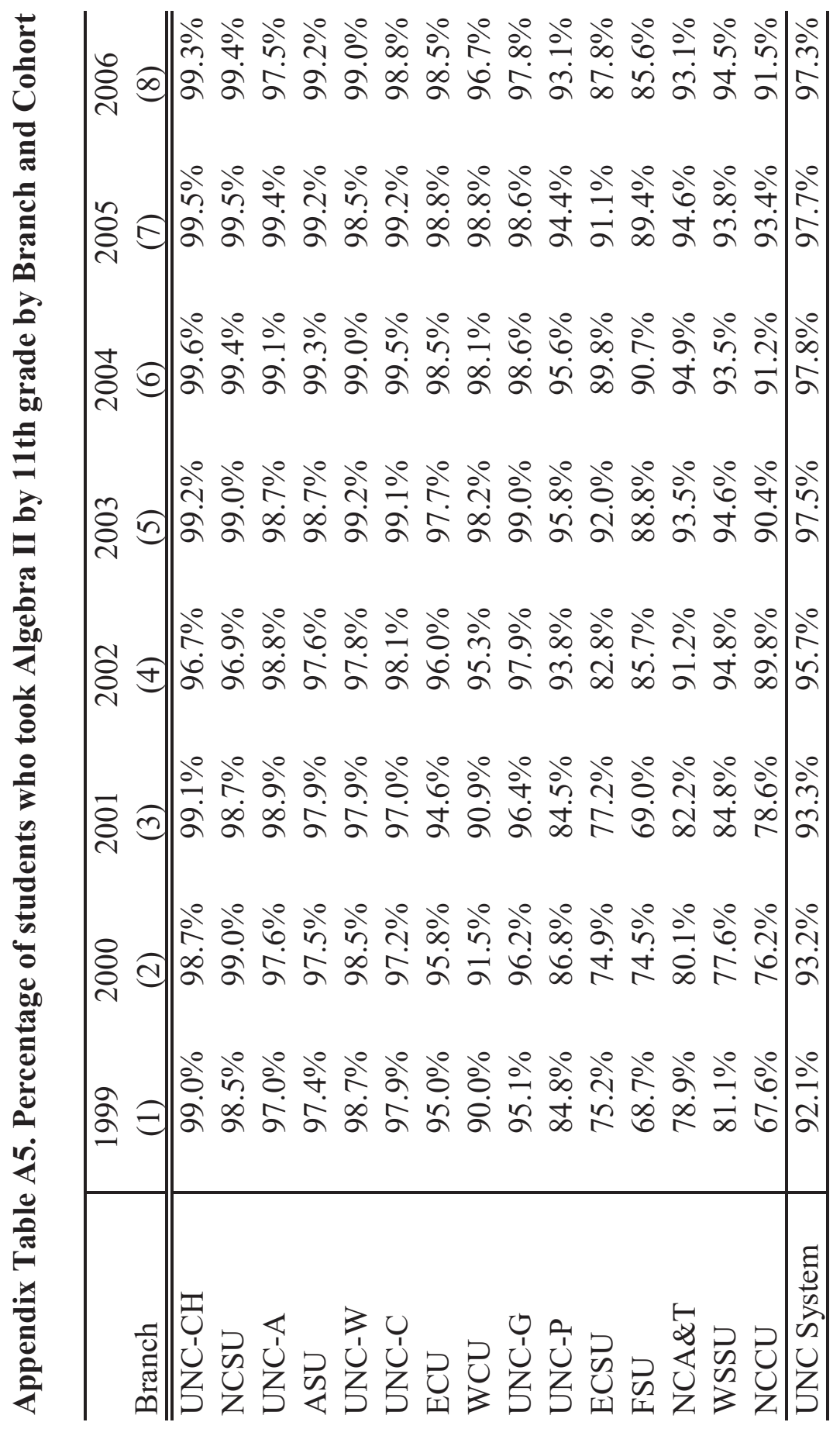

